\title{
TIME DEPENDENT SPECTRAL ANALYSIS OF GROUND MOTION
}

\author{
BY \\ W. W. HAYS \\ T. J. BENNETT \\ M. D. BRUMLEY
}

MARCH 1973

(This is a working paper for the transmission of ideas and exchange of information. The work herein represents the author's opinions and not necessarily those of the Corporation, and the results are preliminary and subject to revision in future reports)

ENVIRONMENTAL RESEARCH CORPORATION

2769 South Highland Drive

Las Vegas, Nevada 89109

\section{PREPARED FOR THE U. S. ATOMIC ENERGY COMMISSION NEVADA OPERATIONS OFFICE CONTRACT NO. AT(29-2)-1163}

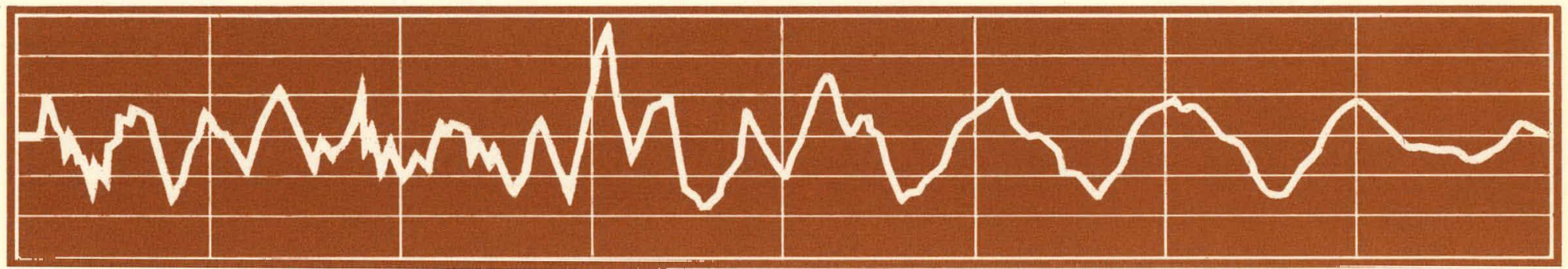

E N $N$ I R

R E S E A R C H

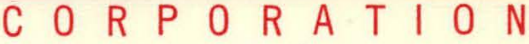

a subs i d i a r y o f c o m p u t e r s c i e n c e s c c o r p o r a t i 


\section{DISCLAIMER}

This report was prepared as an account of work sponsored by an agency of the United States Government. Neither the United States Government nor any agency Thereof, nor any of their employees, makes any warranty, express or implied, or assumes any legal liability or responsibility for the accuracy, completeness, or usefulness of any information, apparatus, product, or process disclosed, or represents that its use would not infringe privately owned rights. Reference herein to any specific commercial product, process, or service by trade name, trademark, manufacturer, or otherwise does not necessarily constitute or imply its endorsement, recommendation, or favoring by the United States Government or any agency thereof. The views and opinions of authors expressed herein do not necessarily state or reflect those of the United States Government or any agency thereof. 


\section{DISCLAIMER}

Portions of this document may be illegible in electronic image products. Images are produced from the best available original document. 
NOTICE

"This report was prepared as an account of work sponsored by the United States Government. Neither the United States nor the United States Atomic Energy Commission, nor any of their employees, nor any of their contractors, subcontractors, or their employees, makes any warranty, express or implied, or assumes any legal liability or responsibility for the accuracy, completeness or usefulness of any information, apparatus, product or process disclosed, or represents that its use would not infringe privately-owned rights."

Available from the

National Technical Information Service

U. S. Department of Commerce

Springfield, Virginia 21151

Price: Paper Copy $\$ 3.00$ per copy

Microfiche $\$ 0.95$

price per 100 pages 
TIME DEPENDENT SPECCTRAL ANALYSIS

OF GROUND MOTION

By

W. W. Hays

T. J. Bennett

M. D. Brumley

March 1973

(This is a working paper for the transmission of ideas and exchange of information. The work herein represents the authors' opinions and not necessarily those of the Corporation, and the results are preliminary and subject to revision in future reports.)

Environmental Research Corporation

2769 South Highland Drive

Las Vegas, Nevada 89109

Prepared for the U. S. Atomic Energy Commission Nevada Operations office Contract No. AT(29-2)-1163 
TABLE OF CONTENTS

ABSTRACT $\ldots \ldots \ldots \ldots \ldots \ldots \ldots \ldots \ldots \ldots \ldots \ldots \ldots \ldots \ldots \ldots \ldots \ldots \ldots$

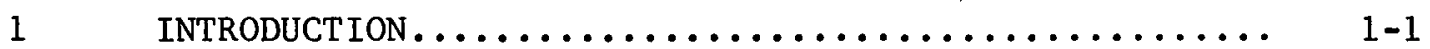

1.1 The Ground Motion Problem................... 1-1

1.2 Background Literature..................... 1-1

1.3 Objective of This Report.................. 1-2

2 BASIC CONCEPTS OF TIME DEPENDENT RESPONSE SPECTRA.... 2-1

2.1 Response Spectra..................... 2-1

2.2 The Response Envelope.................... 2-5

2.3 Examples of Response Envelopes............. 2-7

3 APPLICATION TO GROUND MOTION RESEARCH PROBLEMS....... 3-1

3.1 Surface Wave Dispersion................... 3-1

3.2 Frequency Dependent Site Amplification......... 3-8

3.3 Duration of Ground Motion.................. 3-i1

$4 \quad$ DISCUSSION................................. 4-1

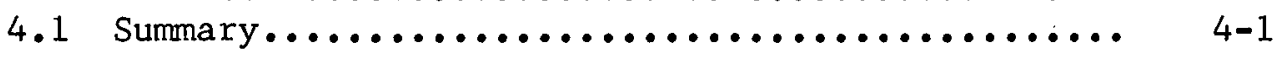

REFERENCES ............................... R-1 


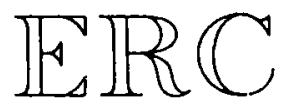

TABLE OF CONTENTS

(Continued)

\section{LIST OF ILLUSTRATIONS}

Figure

Page

1

Single-Degree-of-Freedom Model

$2-2$

2 Relationship of $5 \%$ Damped Response Spectra and

Ground Motion Maxima, Handley Event............. 2-4

3 Block Diagram and Analog Schematic of Filter

System................................. 2-8

4 Output of Filter System for $2 \%$ and $5 \%$ Damped

PSRV Filters.............................. 2-9

5 Response Envelopes Resulting from Set of Four

Different Low-Pass Filter Elements.............. 2-10

6 Output of Filter System for Narrow Band-Pass

Filter Formed by Cascading 4 PSRV Filters.......... 2-11

7 Transient Response of BPF and PSRV (2\%) Filters

to Sine Wave Input........................ 2-13

8 Frequency Response of PSRV and 8 th Order Band-

Pass Filters................................. 2-14

9 Phase Response of Selected Filter Elements......... 2-15

10 Velocity Response Envelope Spectrum for the Handley Velocity Time History, Beatty, Nevada, Alluvium Station...........................

11 Time Histories of Radial Component of Velocity

Recorded at Two Sites in Beatty, Nevada, for

the Handley Event.

12 Velocity Response Envelopes for Periods from

1 to 5 Seconds Derived from the Handley Velocity

Time History, Beatty Hardrock Station.

13 Observed Rayleigh Wave Group Velocities and

Theoretical Dispersion Curve Calculated for a

Near-Surface Structural Model from NTS to Beatty.... 
TABLE OF CONTENTS

(Continued)

\section{LIST OF ILLUSTRATIONS}

Figure

$\underline{\text { Page }}$

14 Approximate Energy Flux for Beatty Hardrock Radial Velocity Time History................. 3-6

15 Approximate Energy Flux for Selected Spectral Components, Beatty Hardrock Radial Velocity Time History........................... 3-7

16 Particle Motion in the Rayleigh Wave Time Window Obtained from 2.0 Second Filtered Velocity Time History, Beatly Hardrock............ 3-9

17 Radial Component Seismogram from Alluvium Station and Body Wave Amplification from Ratios of Velocity Response Envelopes, Beatty Nevada................. 3-10 Contour Plot of Amplification in Body Wave Window..... 3-12

Ratio of Corresponding Beatty Alluvium and Hardrock Radial Component 5\% PSRV Spectra, Handley Event...... 3-13

Time Histories of Radial Component of Ground Motion for Purse and Handley Events Recorded at Beatty, Nevada............................. 3-14

21 Example of Nuclear Explosion Duration Measurement Using Velocity Response Envelopes................ 3-15

22 Response Envelope Spectrum, E1 Centro (1940) N/S Ground Motion (Adapted from United States Atomic Energy Commission Report, NVO-118).

Response Envelope Spectrum, Parkfield (1966) N $65^{\circ} \mathrm{E}$ Ground Motions (Adapted from United States Atomic Energy Commission Report, NVO-118).

Example of Earthquake Duration Measurements Using Velocity Response Envelopes. 


\section{$\mathbb{E} \mathbb{R} \mathbb{C}$}

ABSTRACT

Analog computer signal analysis techniques have been developed to extract time dependent information from a seismogram. A three-element filter system consisting of a narrow band-pass filter, an absolute value operator and a low-pass filter transforms a nuclear detonation or earthquake ground motion time history into a set of response time histories and response envelopes. Each response time history and envelope displays the time dependence of amplitude changes in a seismogram for a discrete range of frequencies and has a physical correspondence to the response of a single-degree-of-freedom, viscously damped, harmonic oscillator. The diagnostic information obtained from application of these signal analysis tools to seismograms recorded at Beatty, Nevada, for underground nuclear explosions at the Nevada Test Site demonstrates their usefulness for studying surface wave propagation, frequency dependent site amplification, and duration of ground motion. 


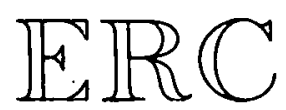

SECTION 1

INTRODUCTION

\subsection{THE GROUND MOTION PROBLEM}

The ground motion caused by an underground nuclear detonation (or earthquake) is the result of a superposition of body and surface waves excited by the detonation (or rupture). These waves interact with the local geology and acquire complex signatures. These signals are often difficult to interpret because of the frequency dependent effects (e.g., dispersion, amplification, scattering, etc.) introduced by geologic inhomogeneities and discontinuities of the earth's crust.

Resolution of complex ground motion signals in terms of geologic parameters is an important objective in engineering seismology. This objective has stimulated seismologists and engineers to seek new ways to extract more information from the seismogram.

\subsection{BACKGROUND LITERATURE}

In recent years, a number of seismologists and structural engineers have developed the concept of filtering a seismogram with a set of narrow band-pass filters to obtain time dependent spectral information. Alexander (1963) used velocity and frequency windows to extract information about individual wave modes. Pilant and Knopoff (1964) applied a time-variable digital filter to measure regional phase velocity. Sutton and Pomeroy (1965) developed analog computer techniques for displaying the seismic signal in different frequency bands as a function of time to aid in identifying seismic wave types. Lynch (1965) developed a system of fastresponse, narrow band-pass filters for analyzing seismic arrivals in terms 


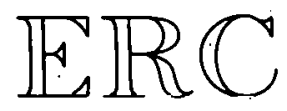

of a band-pass filter spectrum. Archambeau, Flinn and Lambert (1966) analyzed the dispersion of body waves using digital filters. Landisman, Dziewonski and Sato (1969) developed a "moving window analysis" to display the amplitudes and phases of transient seismic signals as a function of period and group velocity. This technique permitted marked improvements in measuring group and phase velocity, particle motion and effects ? caused by excitation and attenuation parameters. Dziewonski, Bloch and Landisman (1969) described a "multiple filter technique" employing a Gaussian shaping function and analyzed multi-mode dispersed signals. Trifunac (1971) extended the multiple filter technique by introducing the concept of the response envelope spectrum (RES), a representation that appeals to the structural engineer because it shows response amplitude as a function of frequency and time. Dziewonski, Mills and Bloch (1972) introduced the "residual dispersion method" of analyzing surface waves, a further extension of the concept of filtering a seismogram with a set of narrow band-pass filters. Perez (1973) used the velocity response envelope spectrum to analyze important engineering parameters of the seismogram recorded at Pacoima dam from the 1971 San Fernando earthquake.

\subsection{OBJECTIVE OF THIS REPORT}

This report will describe preliminary results of research conducted by Environmental Research Corporation (ERC), Ground Motion Contractor to the Atomic Energy Commission's Nevada Operations Office, on time dependent response spectra. The objective is to evaluate the usefulness of time dependent spectral analysis techniques for studying surface wave arrivals, body wave amplification and duration of shaking. 


\section{$\prod_{\Delta} \prod R($}

SECTION 2

BASIC CONCEPTS OF TIME DEPENDENT RESPONSE SPECTRA

\subsection{RESPONSE SPECTRA}

Simple systems such as a viscously damped pendulum or mass-spring system have been successfully used to model soil deposits (Ohsaki, 1969) and structural elements (Blume, Newmark and Corning, 1961). When such a model (Figure 1) is excited by ground motion from a nuclear detonation (or earthquake), it will respond by vibrating. The vibratory motion is described by the well known differential equation (Biot, 1943; Hudson, 1956):

$$
\ddot{x}+2 \omega_{n} h \dot{x}+\omega_{n}^{2} x=-a(t)
$$

where

$$
\begin{aligned}
\mathrm{x} & =\text { relative displacement between the mass and ground } \\
\mathrm{h} & =\text { fraction of critical viscous damping } \\
\omega_{\mathrm{n}} & =\text { undamped natural frequency of vibration of the system } \\
\mathrm{a}(\mathrm{t}) & =\text { ground acceleration }
\end{aligned}
$$

The time dependent solution of this equation for homogeneous initial conditions is given by Duhamel's integral;

$$
x(t)=-\frac{1}{\omega d} \int_{0}^{t} a(r) e^{-h \omega(t-r)} \sin \omega_{d}(t-r) d r
$$

where

$$
\begin{aligned}
\omega_{d}=\omega_{n}\left(1-h^{2}\right)^{\frac{1}{2}}= & \text { damped natural frequency of } \\
& \text { vibration }\left(\text { note: } \omega_{d} \equiv \omega_{n} \text { for } h \leq 0.25\right)
\end{aligned}
$$




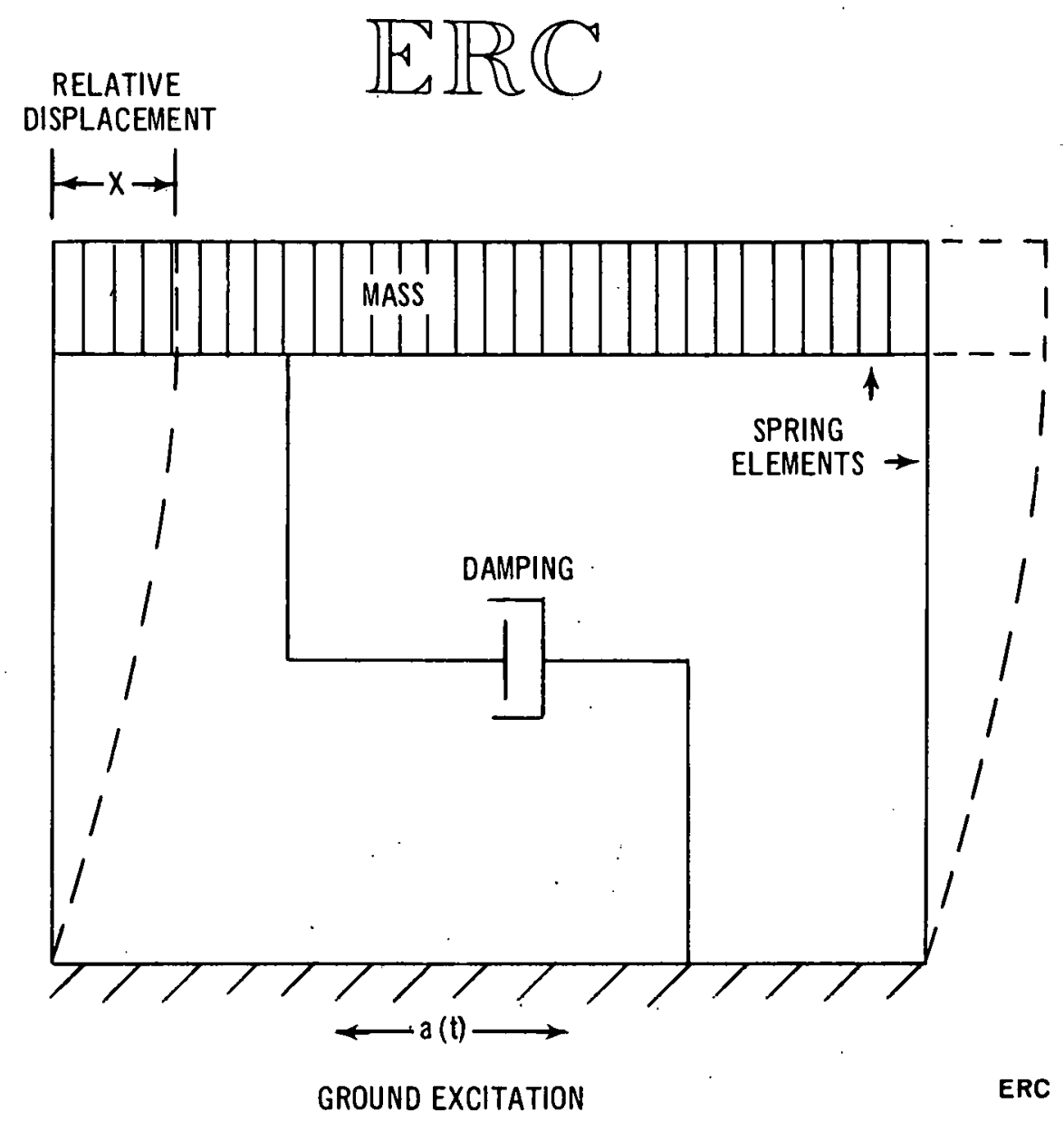

Figure 1. Single-Degree-of-Freedom Model 


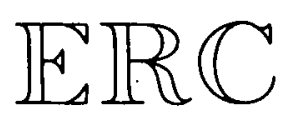

The response spectrum technique, invented by Benioff (1934) and Biot (1943), is a resolution of the recorded ground motion into a display which expresses the maximum amplitudes of response for an ensemble of simple damped oscillators. The various response spectra are defined as follows (Jenschke, et al., 1969):

- Relative Displacement Spectrum (RD)

$$
\operatorname{RD}(\omega)=\underset{t}{\operatorname{SUPREMUM}}|x(t)|
$$

- Relative Velocity Spectrum (RV)

$$
\operatorname{RV}(\omega)=\underset{t}{\operatorname{SUPREMUM}}|\dot{x}(t)| .
$$

- Absolute Acceleration Spectrum (AA) as

$$
\mathrm{AA}(\omega)=\underset{t}{\operatorname{SUPREMUM}}|\ddot{x}(t)+a(t)|
$$

- Pseudo Relative Velocity (PSRV) Spectrum

$$
\operatorname{PSRV}(\omega)=\omega \operatorname{RD}(\omega) \text {, and }
$$

- Pseudo Absolute Acceleration Spectrum (PSAA)

$$
\operatorname{PSAA}(\omega)=\omega^{2} \operatorname{RD}(\omega)
$$

The prefix pseudo used for two of these spectra arises from the fact that they are not derived by finding the maximum values of $\dot{x}(t)$ and $\ddot{x}(t)$.

The relationship between $\mathrm{RD}, \mathrm{PSAA}$ and $\mathrm{PSRV}$, the three response spectra typically used in engineering seismology analyses, and ground motion is clearly displayed on tripartite $\log -\log$ graph paper (Figure 2). For 


\section{$\mathbb{E} \mathbb{R} \mathbb{C}$}

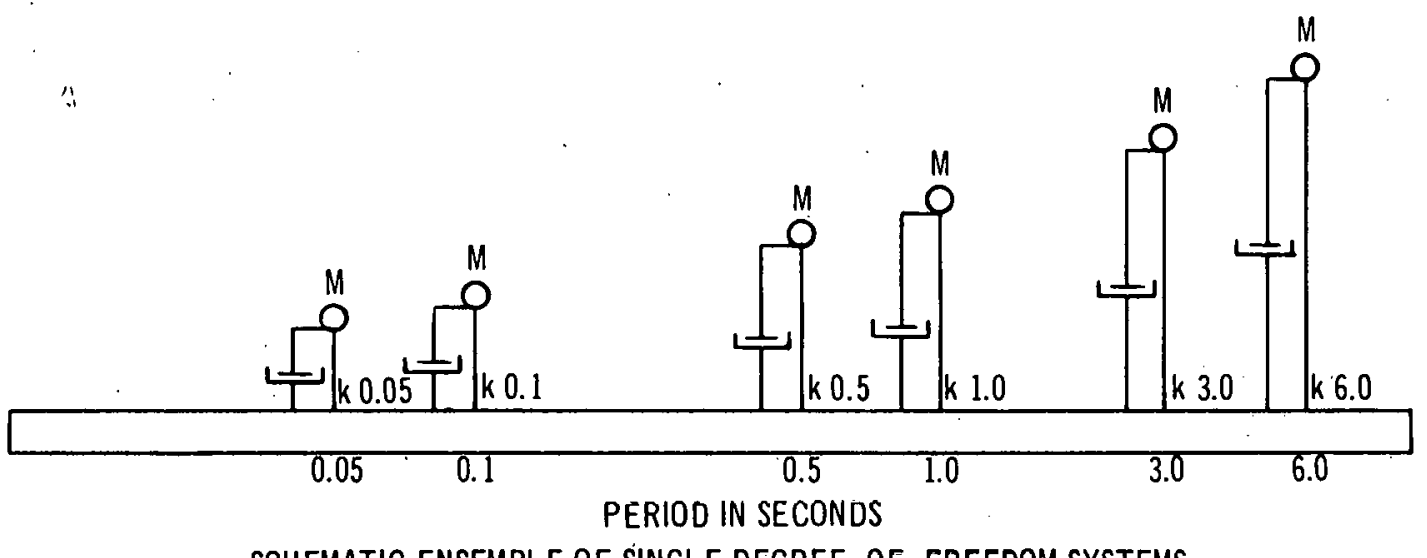

SCHEMATIC ENSEMBLE OF SINGLE DEGREE-OF-FREEDOM SYSTEMS

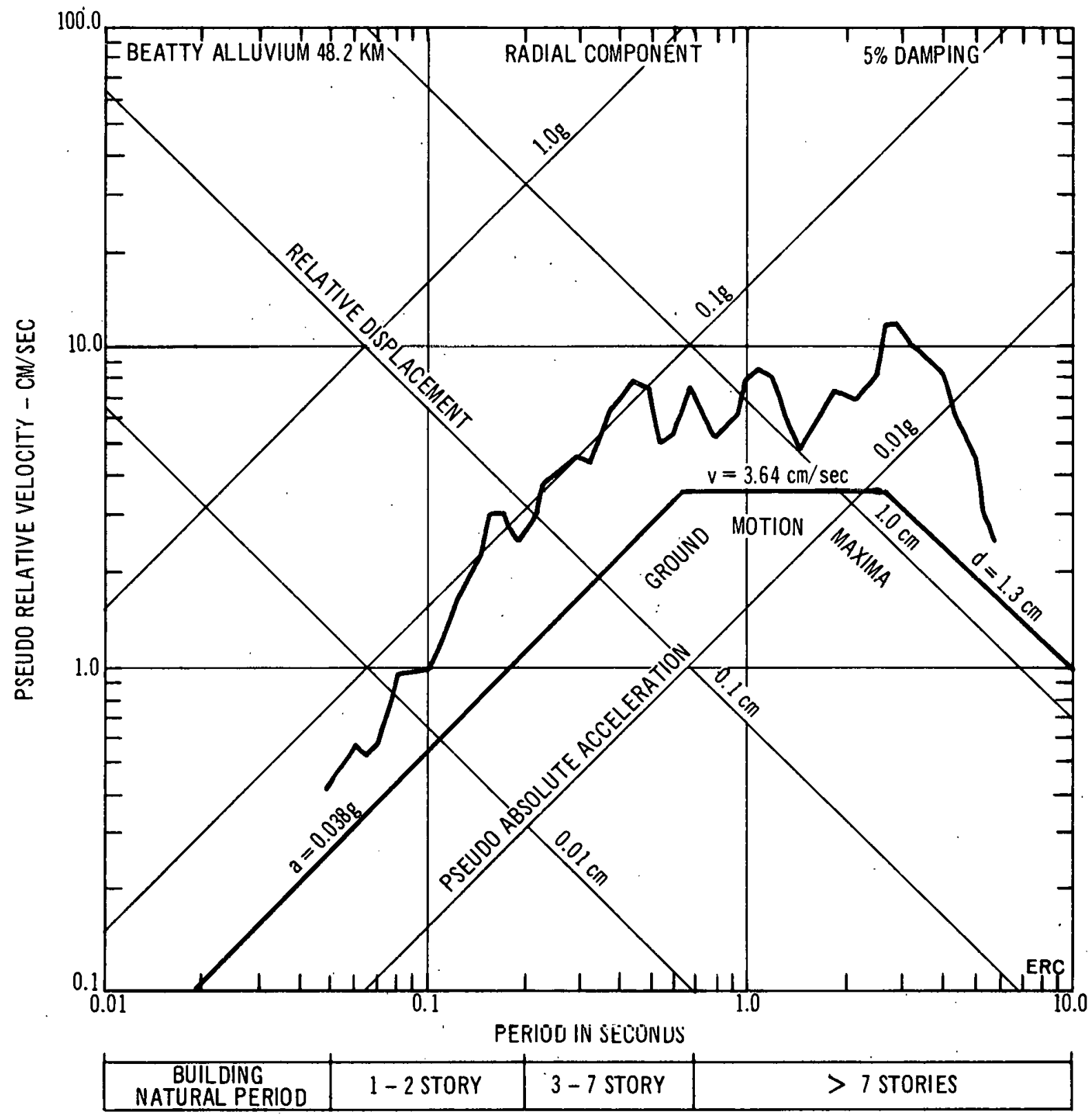

Figure 2. Relationship of 5\% Damped Response Spectra and Ground Motion Maxima, Handley Event 
extremely short periods, spectral acceleration approaches the bound set by maximum ground acceleration; for very long periods, spectral displacement approaches the bound set by maximum ground displacement. For intermediate periods, spectral velocity is amplified relative to the ground velocity. Thus, response spectra characterize both maximum ground motion levels and structural response.

Each response characterization has a physical meaning. PSAA is a measure of the maximum elastic spring force per unit of mass. RD represents the maximum value of the relative displacment of the simple system during vibratory motion. PSRV gives an approximate index of the greatest velocity, relative to its base, of the center of mass of the resonant simple structure. PSRV can also be related to the maximum energy absorbed in the spring. For small damping, the PSRV spectrum is proportional to the smoothed Fourier amplitude spectrum (Hudson, 1956).

\subsection{THE RESPONSE ENVELOPE}

The steady state part of the relative response is defined by

$$
x(t)=\frac{\left(\frac{\omega}{\omega_{n}}\right)^{2}}{\sqrt{\left[1-\left(\frac{\omega}{\omega_{n}}\right)^{2}\right]^{2}+\left(2 \frac{\omega h}{\omega_{n}}\right)^{2}}} \cdot A \sin (\omega t-\phi)
$$

if $-A \omega^{2}$ sin $\omega t$ is substituted for $a(t)$ and

$$
\phi=\arctan \left(\frac{2 \omega_{n} \omega h}{\omega_{n}^{2}-\omega^{2}}\right) .
$$


The factor

$$
\frac{1}{\sqrt{\left[1-\left(\frac{\omega}{\omega_{\mathrm{n}}}\right)^{2}\right]^{2}+\left(2 \frac{\omega h}{\omega_{\mathrm{n}}}\right)^{2}}}
$$

can be considered as a dynamic amplification factor. It has a maximum value of $\frac{1}{2 h}$ when $\omega=\omega_{n}$. Thus, a typical, lightly-damped, single degree-of-freedom system acts like a narrow band-pass filter. This filter amplifies frequencies of the input ground motion centered around $\omega_{n}$ by $\frac{1}{2 h}$ times and follows the input wave form with a delay of $\frac{\pi}{2}$. The envelope of the response of the single degree-of-freedom oscillator is, therefore, approximately $\frac{A(t)}{2 h}$, when $A=A(t)$ is a slowly varying function of time.

Calculating response envelopes for a set of these narrow band-pass filters enables the input ground motion time history (acceleration, velocity or displacement), to be characterized in terms of its time dependent spectral composition. A three-dimensional diagram, called a response envelope spectrum (RES) (Trifunac, 1971), is constructed from the set of envelopes. RES displays the time and frequency dependence of any selected harmonic component of ground motion. Any of the spectrum representations for velocity, acceleration or displacement, can be constructed from a given RES using the relations noted in Section 2.1 . 


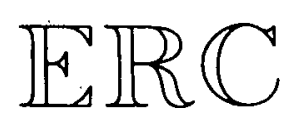

\subsection{EXAMPI.ES OF RESPONSE ENVELOPES}

Figure 3 illustrates the basic concept of the multiple filtration process used to derive response envelopes on an analog computer. A seismogram is input to a filter system consisting of three elements: 1) a narrow band-pass filter (the hcart of the system), 2) an absolute value operator, and 3) a low-pass filter. The output of the total filter system for each narrow band-pass filter is a response envelope. RES is the display pertaining to a set of such envelopes.

Figure 4 illustrates the difference in output of the filter system for two different narrow band-pass filters. The same nuclear explosion velocity time history is the input in each case. The two narrow band-pass filters correspond physically to the PSRV of a single-degree-of-freedom, damped, harmonic oscillator having a natural frequency of $1 \mathrm{~Hz}$. The damping values are, respectively, $2 \%$ and $5 \%$ of critical.

The effect of the low-pass filter element is illustrated in Figure 5. Four different low-pass filters are used to derive a response envelope for the time history output of the 5\%. damped, $1 \mathrm{~Hz}$ PSRV filter. The low-pass filter having a corner frequency, Fc, equal to 0.316 of the center frequency ( $1 \mathrm{~Hz}$ in this example) of the PSRV filter gives an optimum filtration effect, and is used in the applications discussed in Section 3.

Figure 6 illustrates corresponding quantities as in Figure 4 for a special narrow band-pass filter formed by cascading 4 PSRV filters. Each individual filter has damping equal to $50 \%$ of critical. The resultant filter corresponds to an 8th order, band-pass filter (BPF́). This filter, 

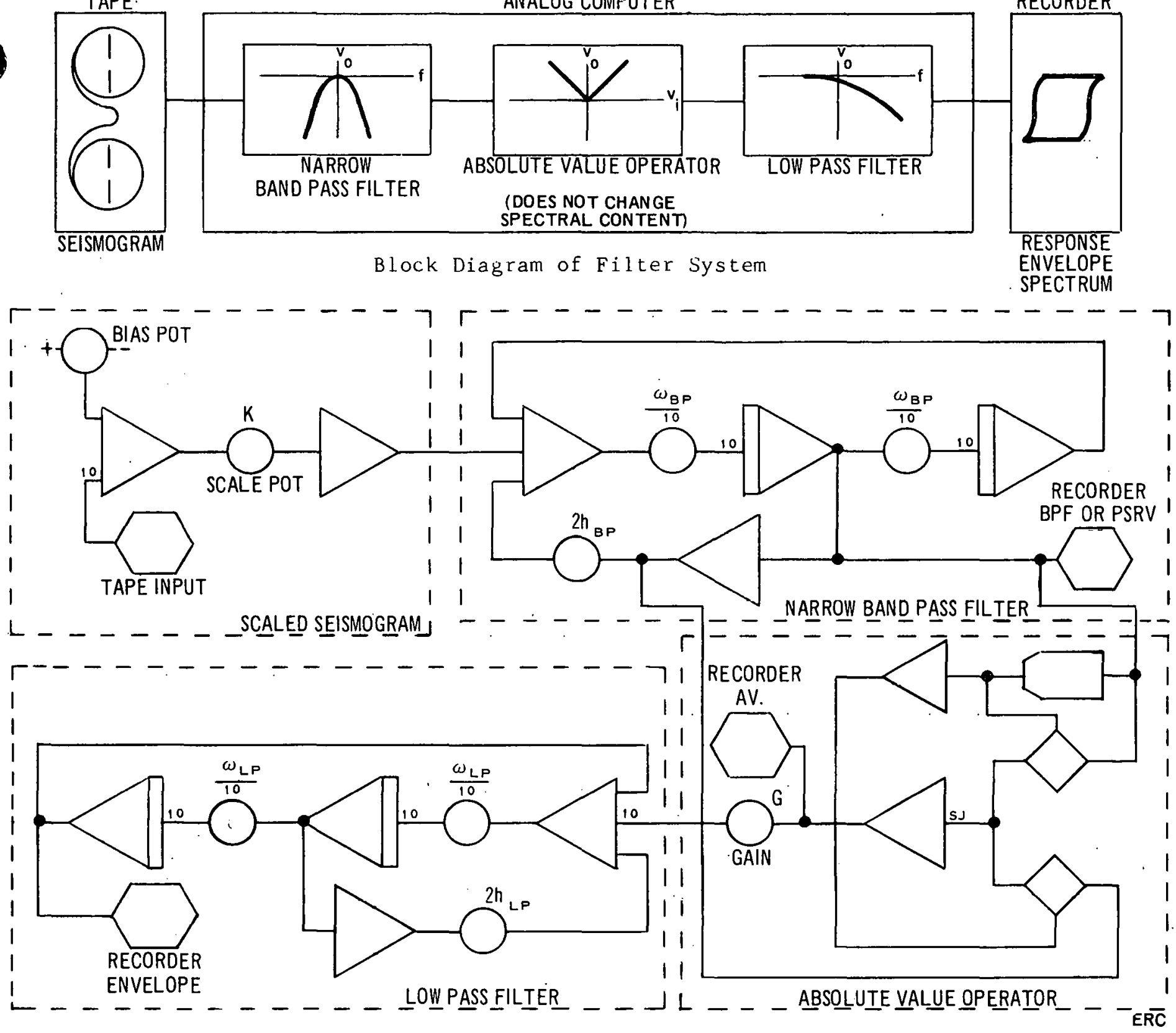

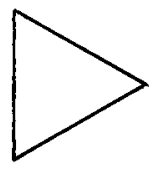

AMPLIFIER

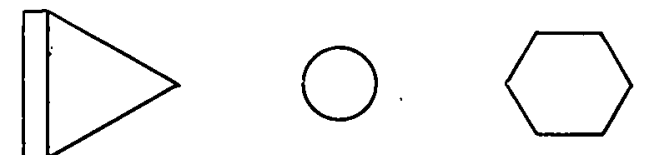

INTEGRATOR POTENTIOMETER RECORDER

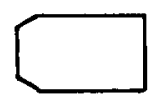

ELECTRONIC COMPARATOR

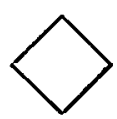

ELECTRONIC

SWITCHES

Analog Schematic of Filter System

Figure 3. Block Diagram and Analog Schematic of Filter System 
$\mathbb{E} \mathbb{R} \mathbb{C}$
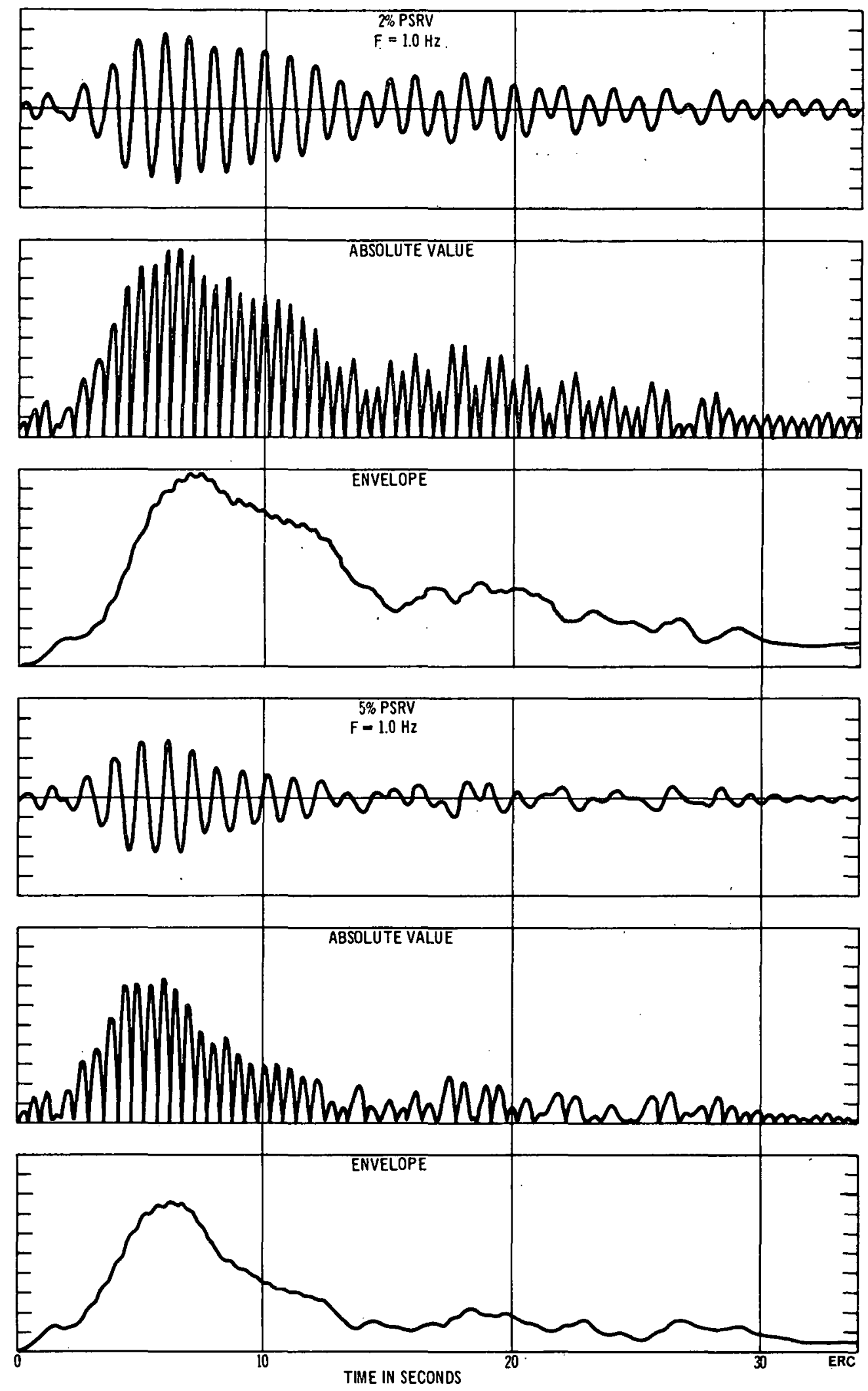

NOTE: VERTICAL SCALE OF ABSOLUTE VALUE AND ENVELOPES ARE THE SAME

Figure 4. Output of Filter System for $2 \%$ and $5 \%$ Damped PSRV. Filters 


\section{$\mathbb{E} \mathbb{R} \mathbb{C}$}
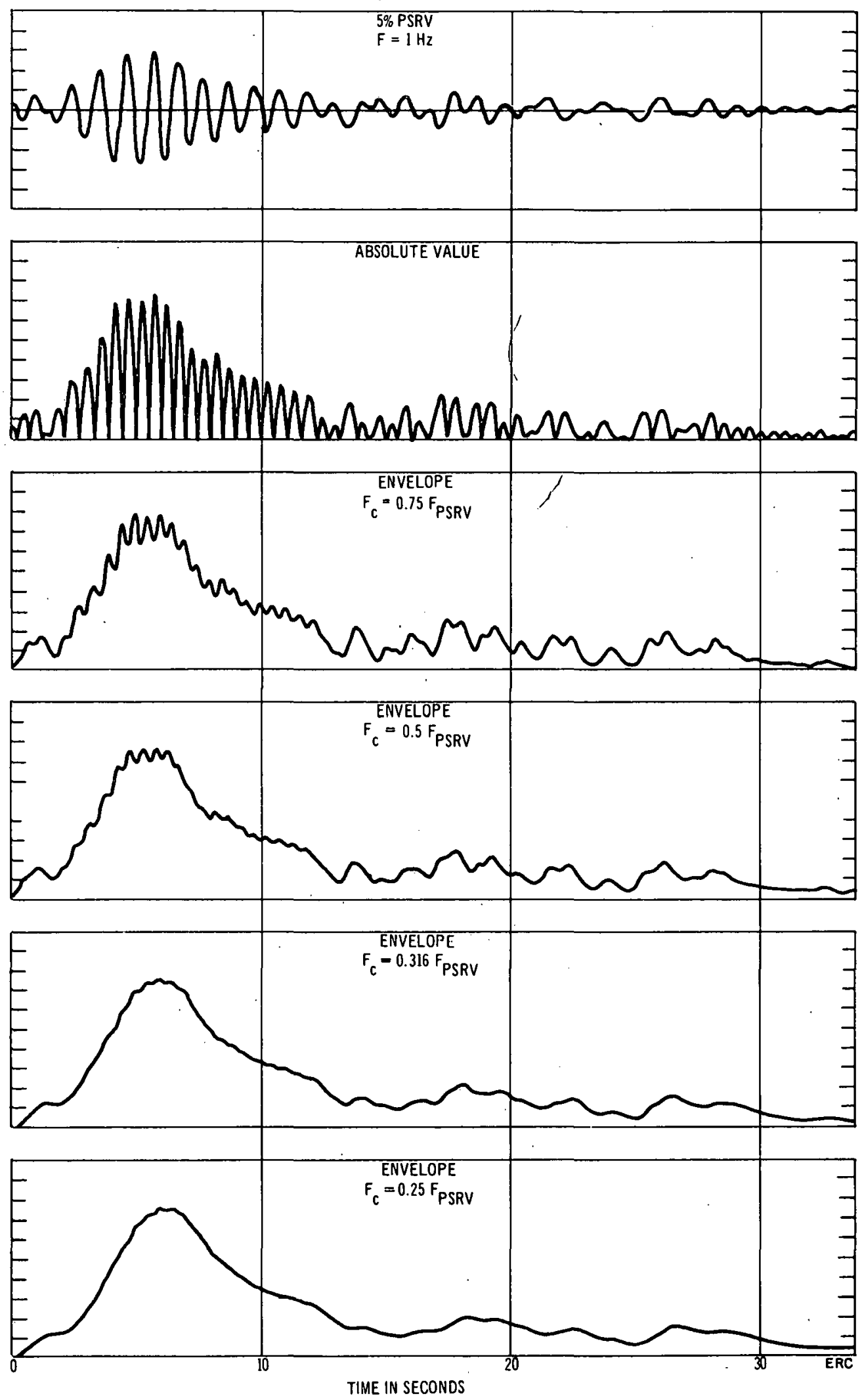

NOTE: VERTICAL SCALE OF ABSOLUTE VALUE AND ENVELOPES ARE THE SAME

Figure 5. Response Envelopes Resulting from Set of Four Different Low-Paes Filter Elcment 3 


\section{$\mathbb{E} \mathbb{R} \mathbb{C}$}
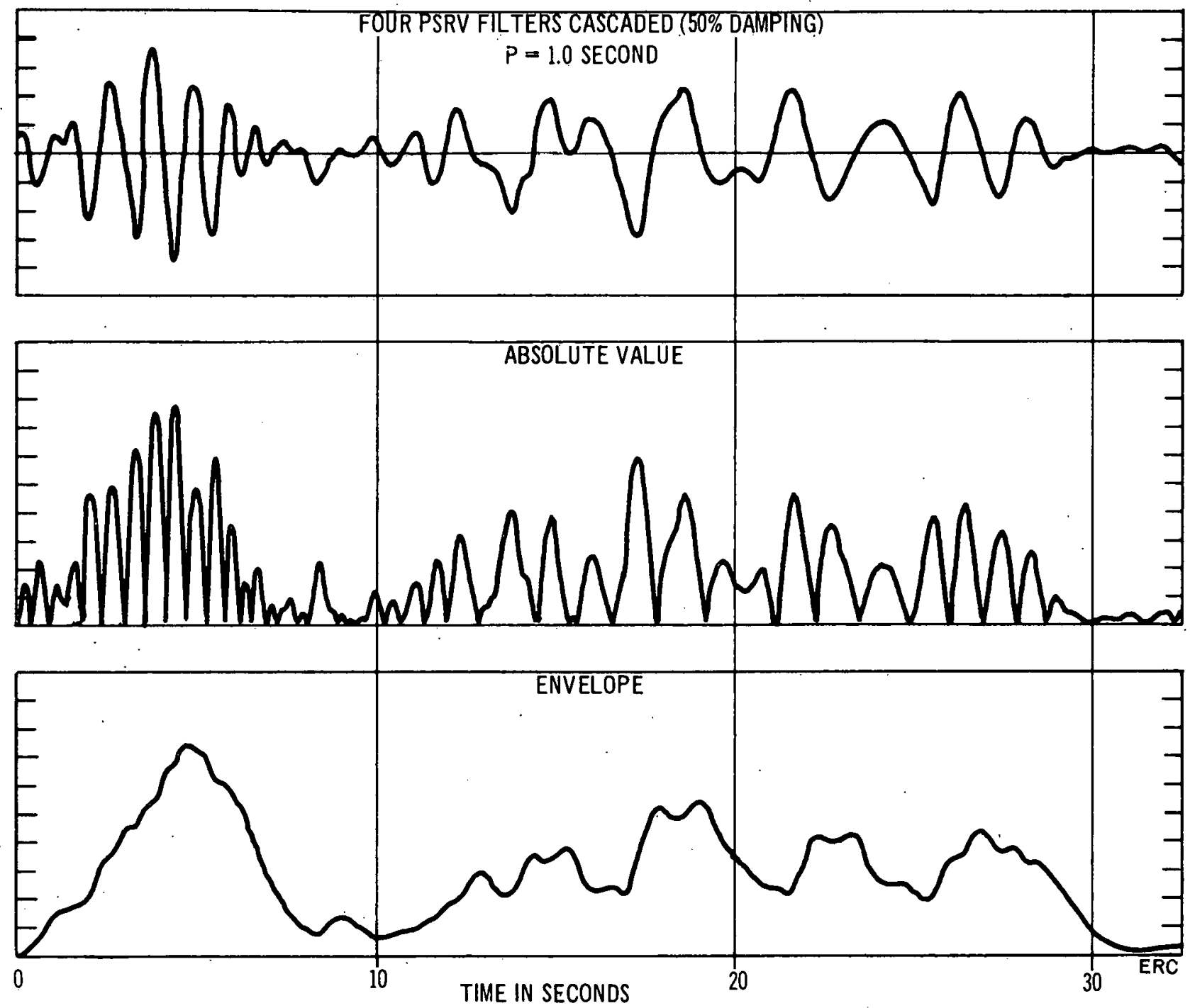

Figure 6. Output of Filter System for Narrow Band-Pass Filter Formed by Cascading 4 PSRV Filters 


\section{$\mathbb{E} \mathbb{R C}$}

although not widely used today, was used in the AEC ground motion program several years ago to characterize ground motion. BPF's merit lies in its quick transient response and narrow frequency bandwidth (Figures 7 and 8 ).

Figure 9 illustrates the phase response for several filter elements. Corrections for relative phase shifts are made on the basis of these curves when applying these signal analysis tools to study specific ground motion problems in detail.

Figure 10 illustrates a REŚ for a representative radial component velocity time history recorded at Beatty, Nevada, from the Handley detonation at Nevada Test Site. Information can be extracted from this display that cannot be obtained from a standard response spectrum (see Figure 2). Applications of these analysis techniques and the additional insight they provide to ground motion research problems will be discussed in Section 3. 


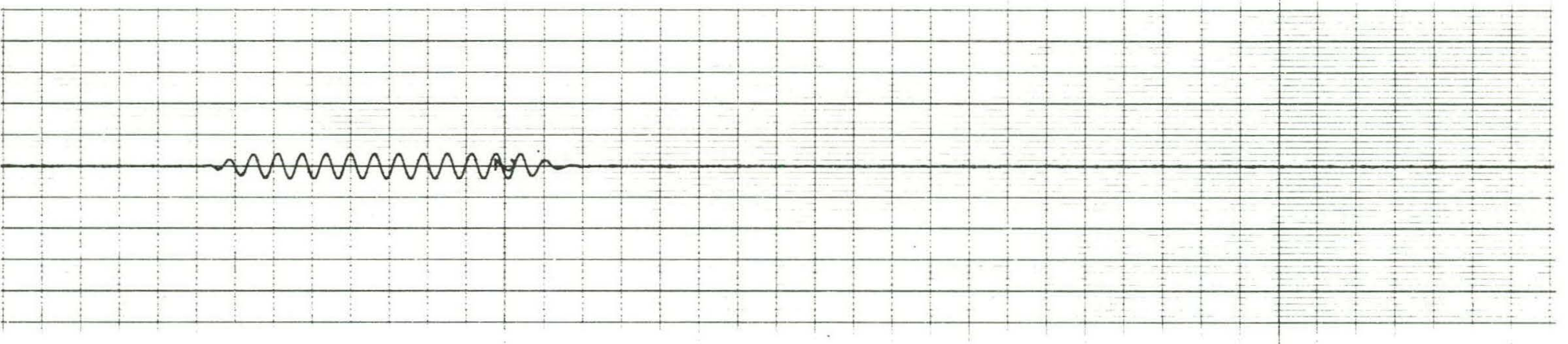

$\operatorname{PSRV}(\mathrm{t})=$

PSRV OUTPUT

(2\% DAMPING)

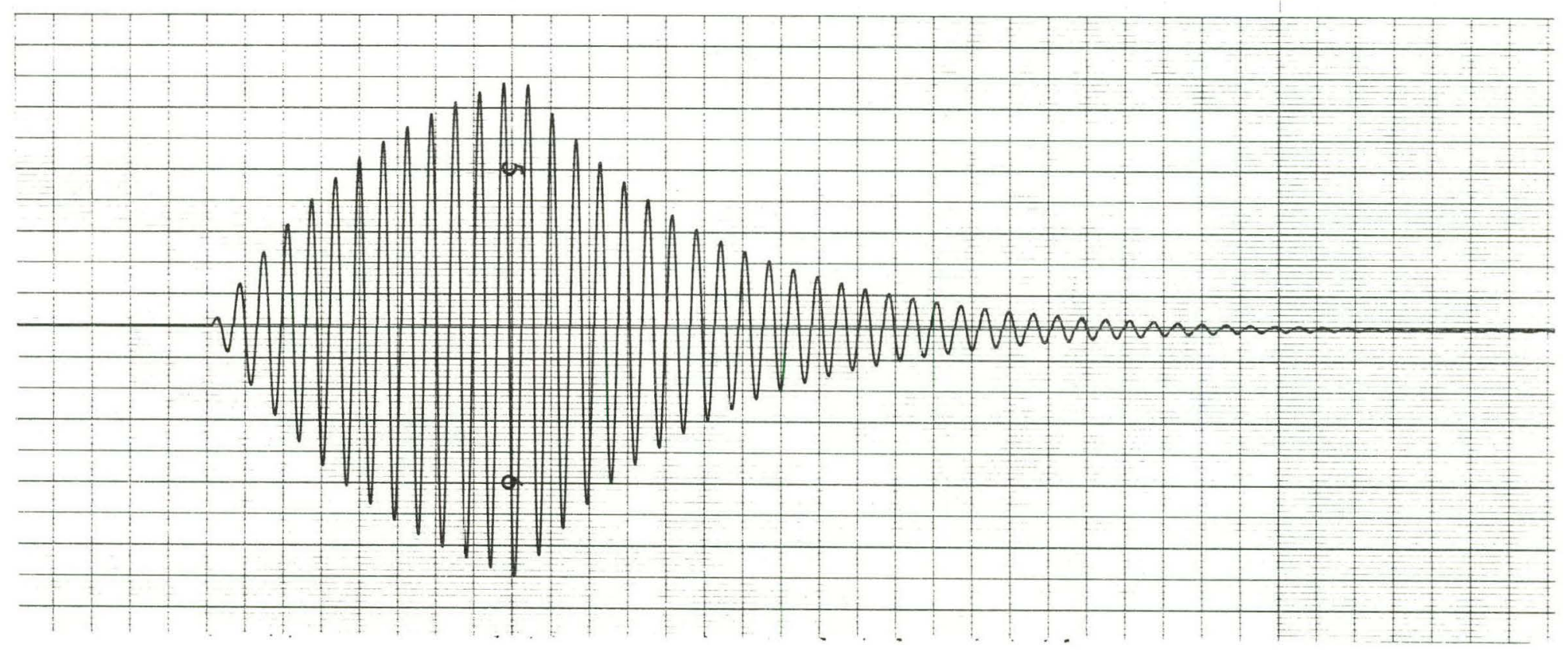

Figure 7. Transient Response of BPF and PSRV (2\%) Filters to Sine Wave Input 

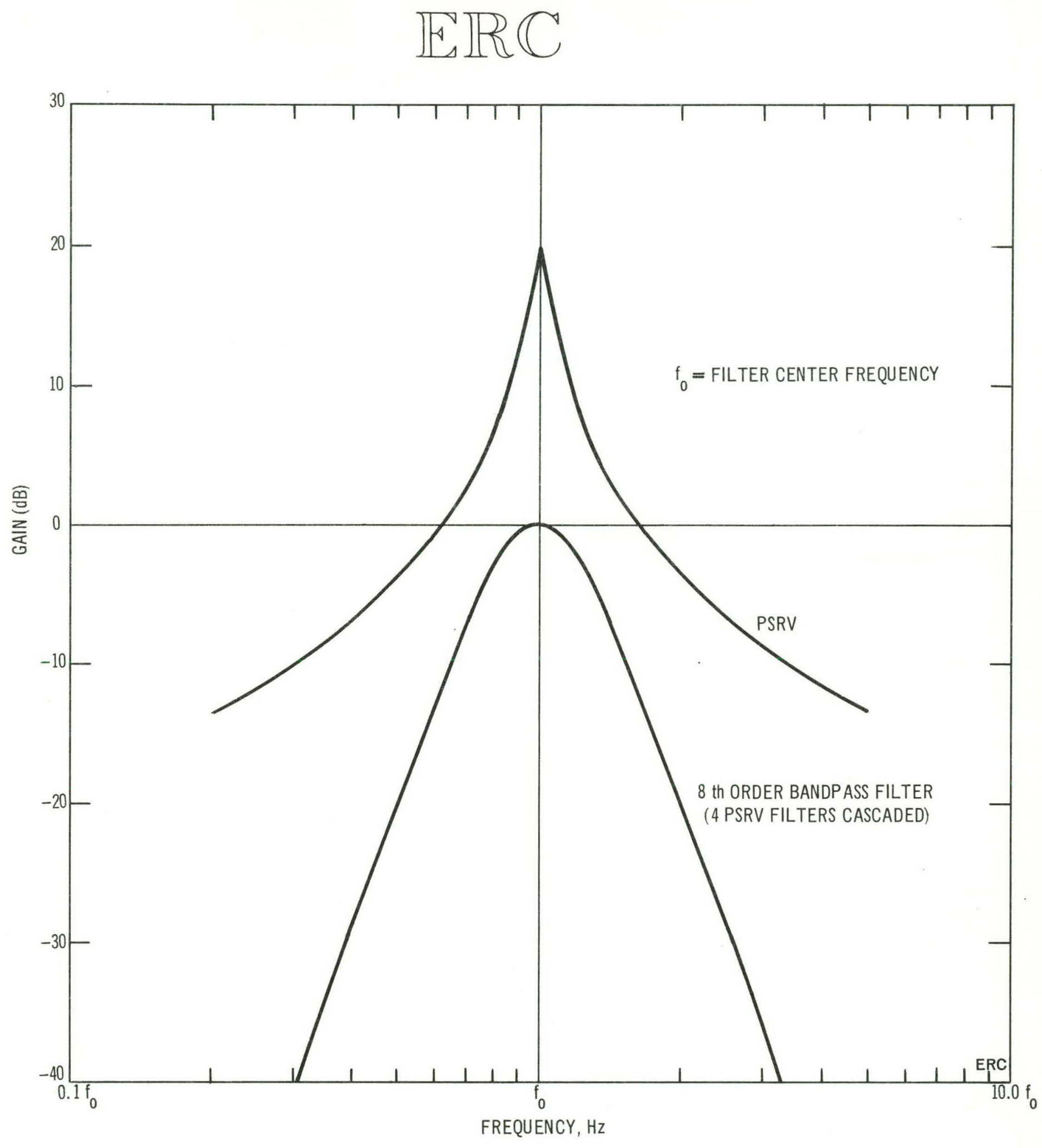

Figure 8. Frequency Response of PSRV and 8th Order Band-Pass Filters 
$\mathbb{E} \mathbb{R} \mathbb{C}$
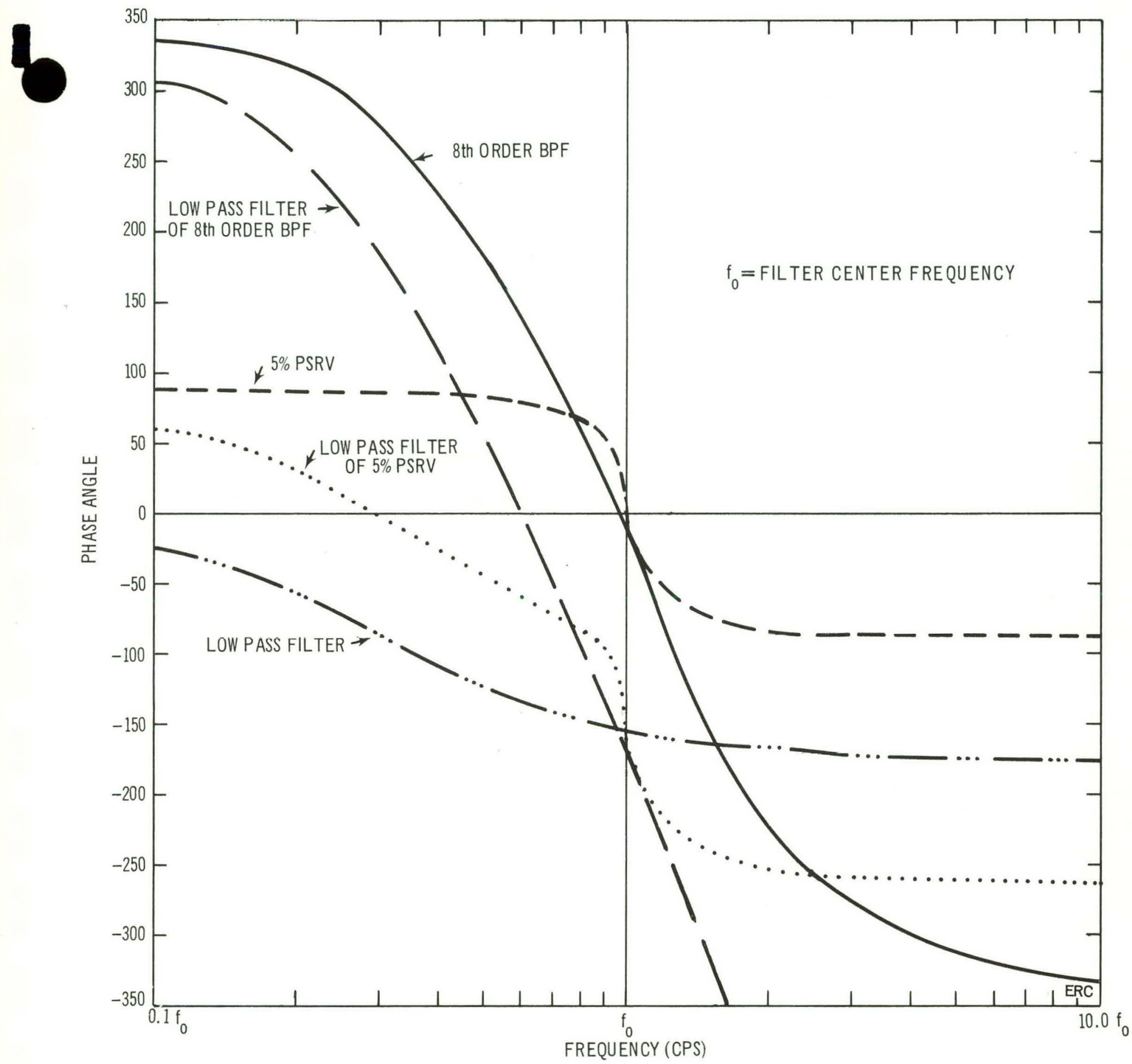

Figure 9. Phase Response of Selected Filter Elements 


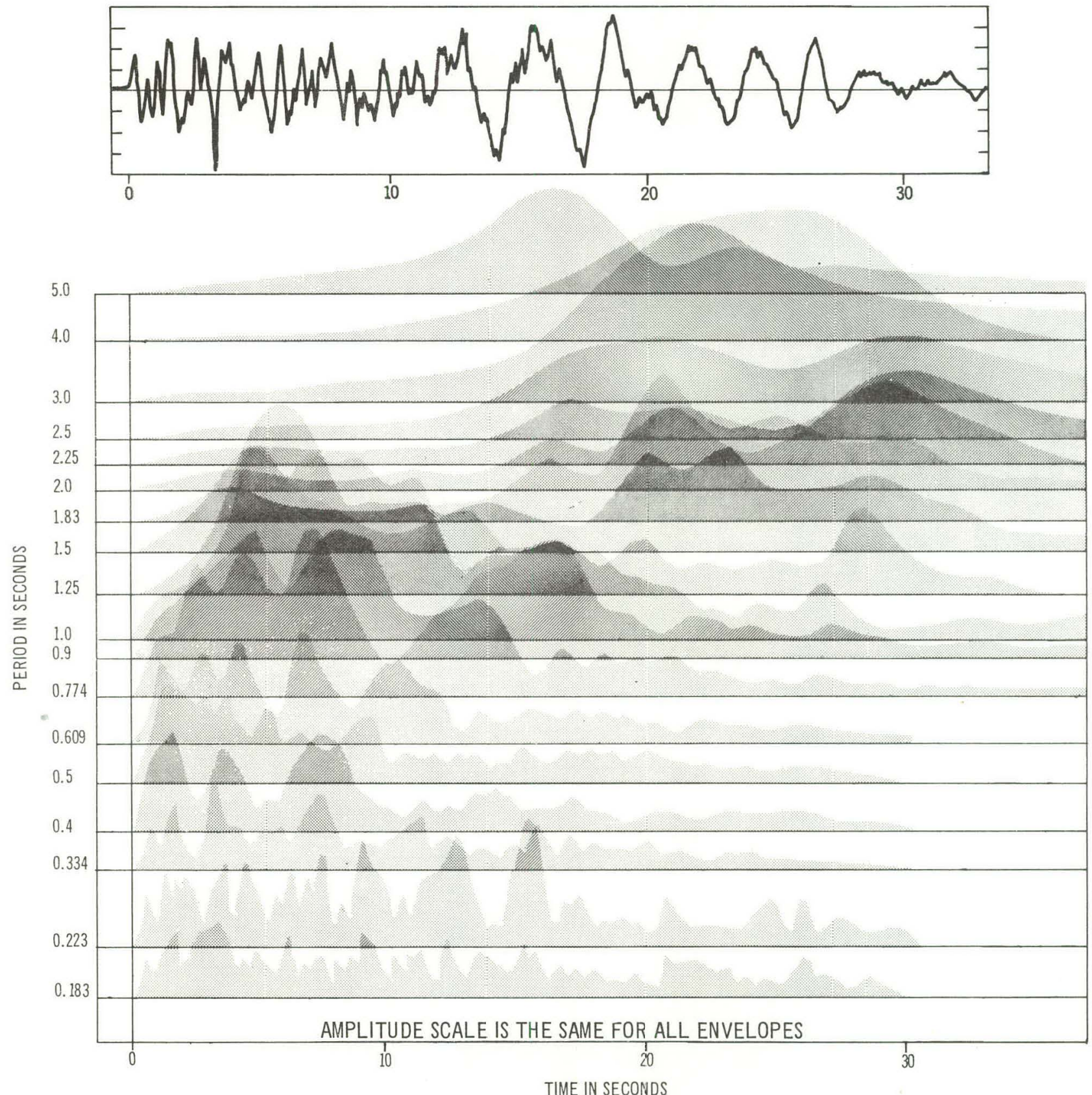

Figure 10. Velocity Response Envelope Spectrum for the Handley Velocity Time History, Beatty, Nevada, Alluvium Station 


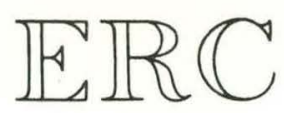

\section{SECTION 3}

\section{APPLICATION TO GROUND MOTION RESEARCH PROBLEMS}

The location of a pair of seismograph stations located in Beatty, Nevada, is shown in Figure 11. The two stations are separated by 4,400 feet and are sited respectively on alluvium and sandstone. The radial component velocity seismogram pair, recorded from the Handley event, 29 miles away at NTS, is also illustrated in Figure 11. The seismic response of these two sites is well known; therefore, they will be used as a model to evaluate the usefulness of time dependent spectral analysis techniques to study: 1) surface wave propagation characteristics, 2) frequency dependent site amplification, and 3) duration of ground motion.

In the following subsections, the discussion will center primarily on the use of the 5\% PSRV filter. The basic applications, however, are similar for any of the narrow band-pass filters.

\subsection{SURFACE WAVE DISPERSION}

Figure 12 illustrates response envelopes for eight periods ranging from 1 to 5 seconds for the Handley hardrock velocity time history. The individual response envelopes display peaks corresponding to wave energy maxima. In the surface-wave window, the peaks corresponding to the fundamental Rayleigh mode shift progressively from late to early time with increase in period between 2 and 5 seconds. This represents normal dispersion of group velocity. Some indication of inverse dispersion in the fundamental mode for periods less than 2 seconds is also evident. Minor peaks at earlier times in the surface-wave window probably indicate the 
BEATTY ALLUVIUM

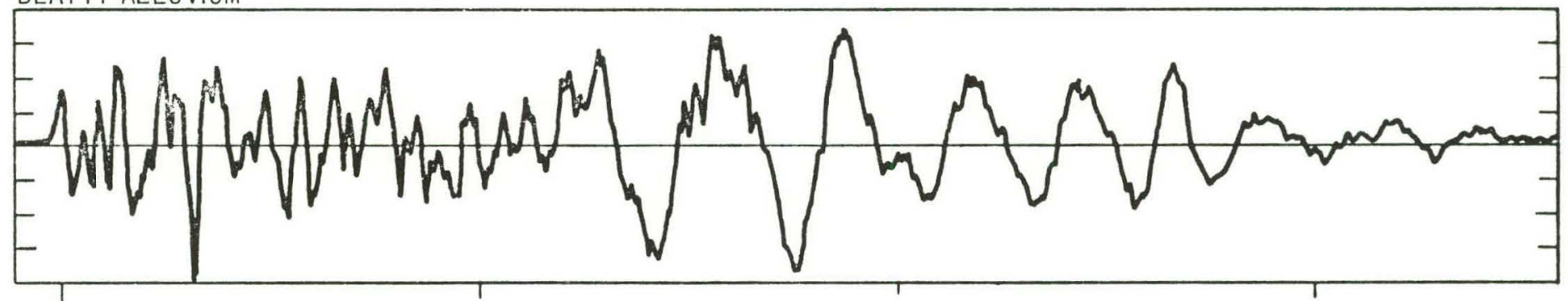

SAME VERTICAL SCALE

BEATTY HARDROCK
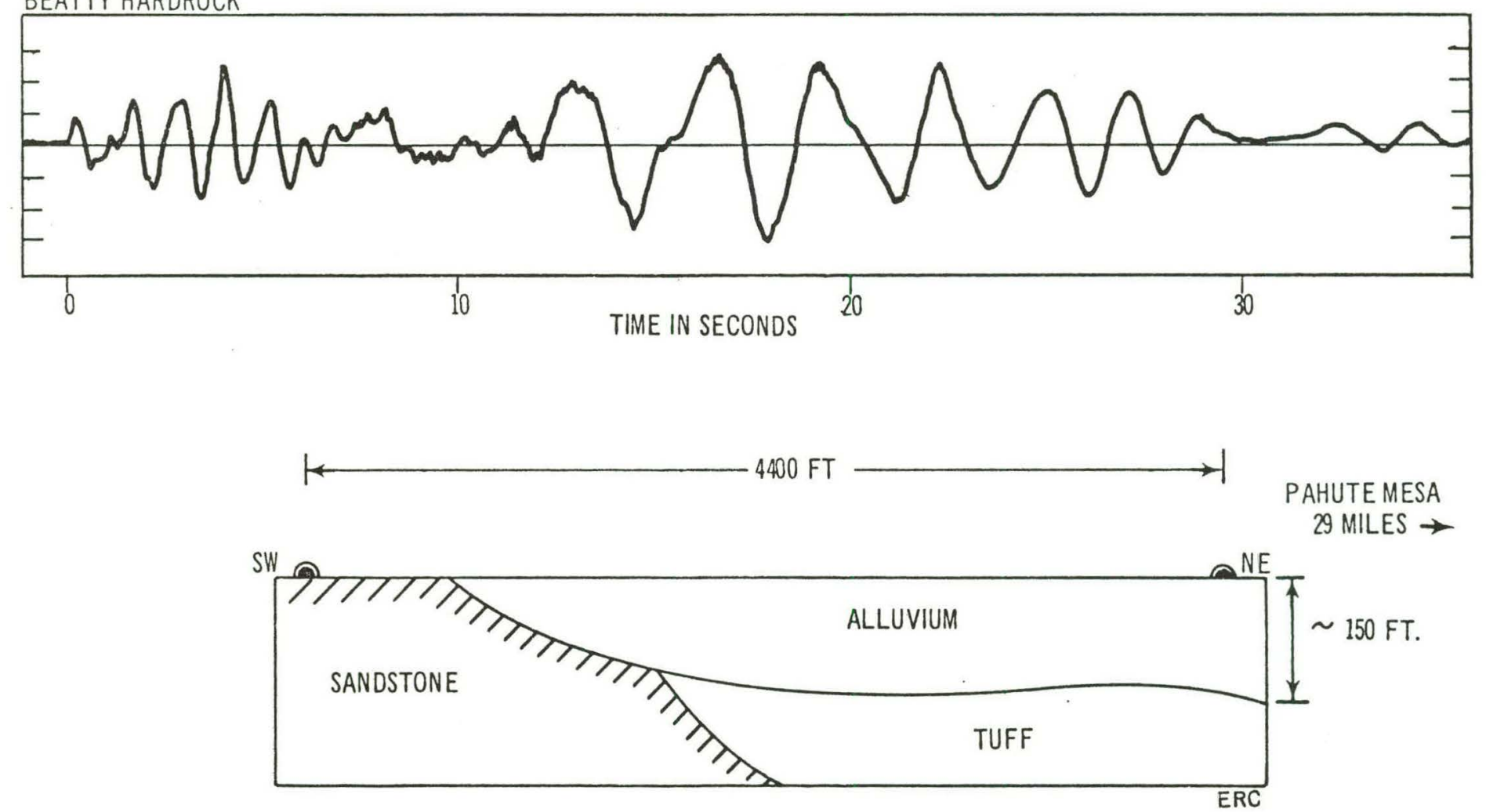

Figure 11. Time Histories of Radial Component of Velocity Recorded at Two Sites in Beatty, Nevada, for the Handley Event 


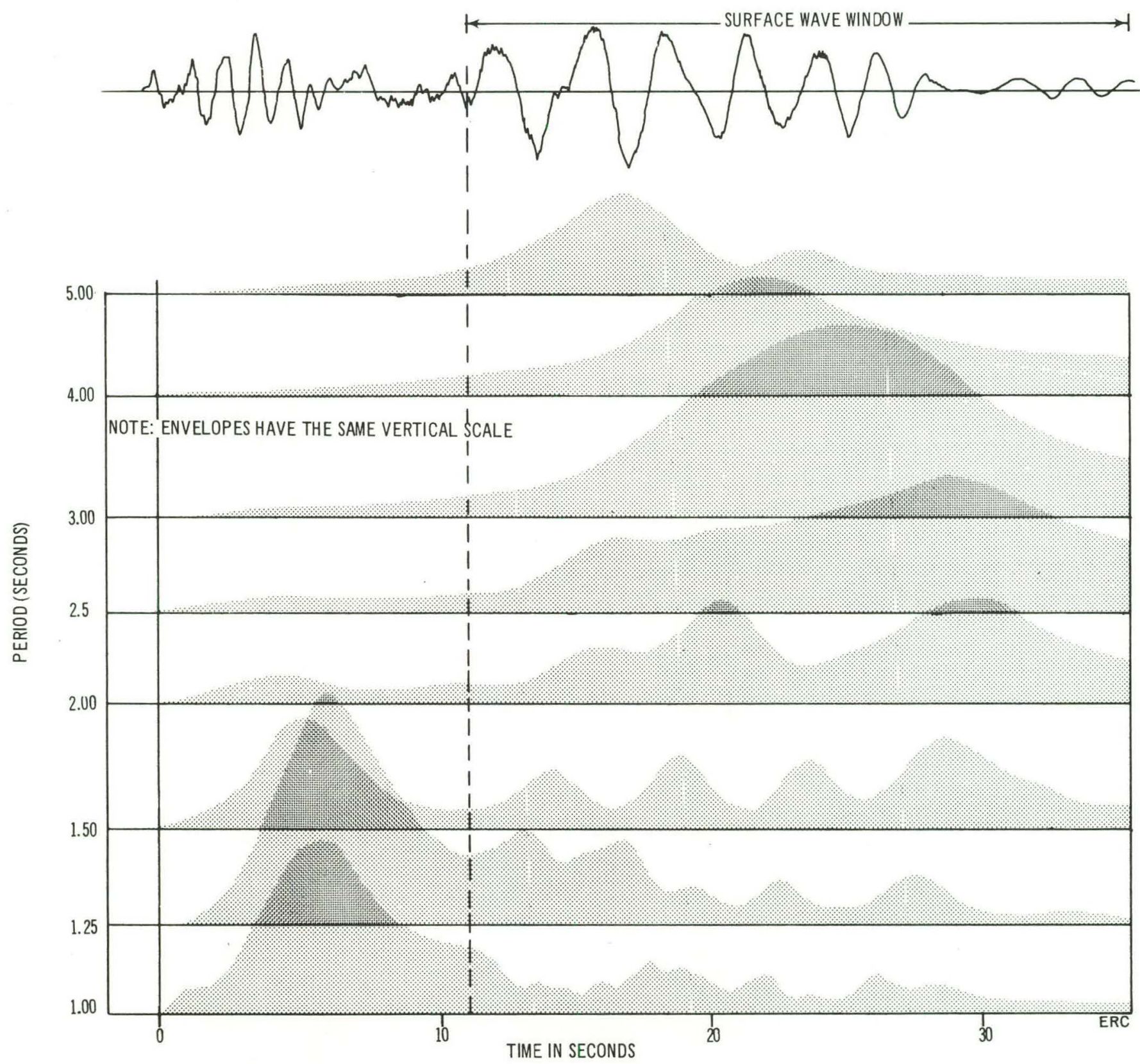

Figure 12. Velocity Response Envelopes for Periods from 1 to 5 Seconds Derived from the Handley Velocity Time History, Beatty Hardrock Station 
presence of higher wave modes. Thus, response envelopes may also be useful for mode separation. The observed group velocity values extracted from the Handley hardrock velocity time history (Figure 12) are compared in Figure 13 with theoretical values calculated from the structural model, using the procedure described by Haskell (1953) and Dunkin (1965). The geologic model consists of a near surface layer approximately $1.5 \mathrm{~km}$ thick overlying a half-space. The theoretical dispersion curve is in good agreement with the observed data. This geologic model, although simple, is a reasonable approximation to the average regional geologic configuration (Johnson, 1965).

It is instructive to examine the energy content of the Beatty hardrock seismogram. Figure 14 illustrates the radial velocity seismogram, $v(t)$, and two other plots which correspond, respectively, to $v(t)^{2}$ and $\int \mathrm{v}(\mathrm{t})^{2} \mathrm{dt}$. The latter plot is an approximate index of the energy flux with time and shows that the maximum energy content of the seismogram correlates with waves in the surface wave window.

Figure 15 presents these relative energy flux plots. for the eight spectral components analyzed earlier. Each individual plot represents the integral of the squared time history response of a $5 \%$ damped PSRV filter. Physically, these plots correspond to the amount of energy stored in the spring element of a simple structural model when subjected to a ground motion. These illustrations show that most of the energy in a given period band arrives at a fairly uniform rate over a time interval of 5-10 seconds duration. Both the rate and duration vary somewhat for each spectral component. Most of the energy in the seismograms is concentrated near 3 seconds period. 


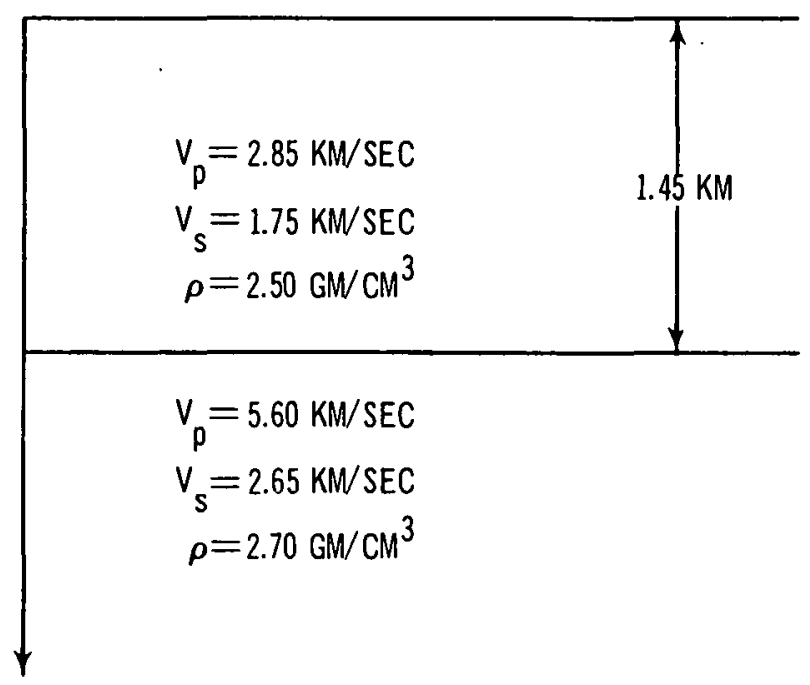

- OBSERVED GROUP VELOCITIES

DISPERSION CURVE COMPUTED FROM MODEL

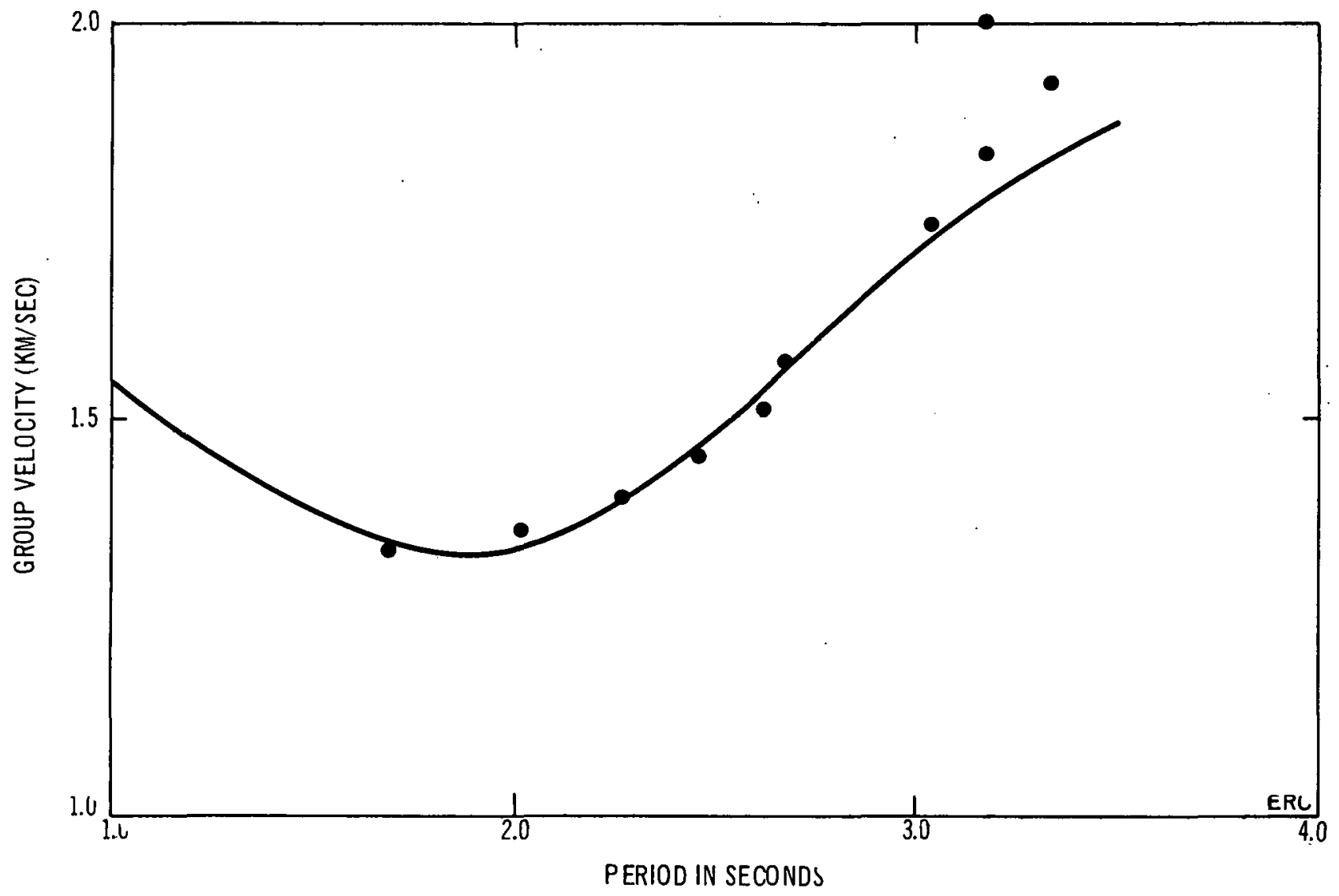

Figure 13. Observed Rayleigh Wave Group Velocities and Theoretical. Dispersion Curve Calculated for a Near-Surface Structural Model from NTS to Beatty 


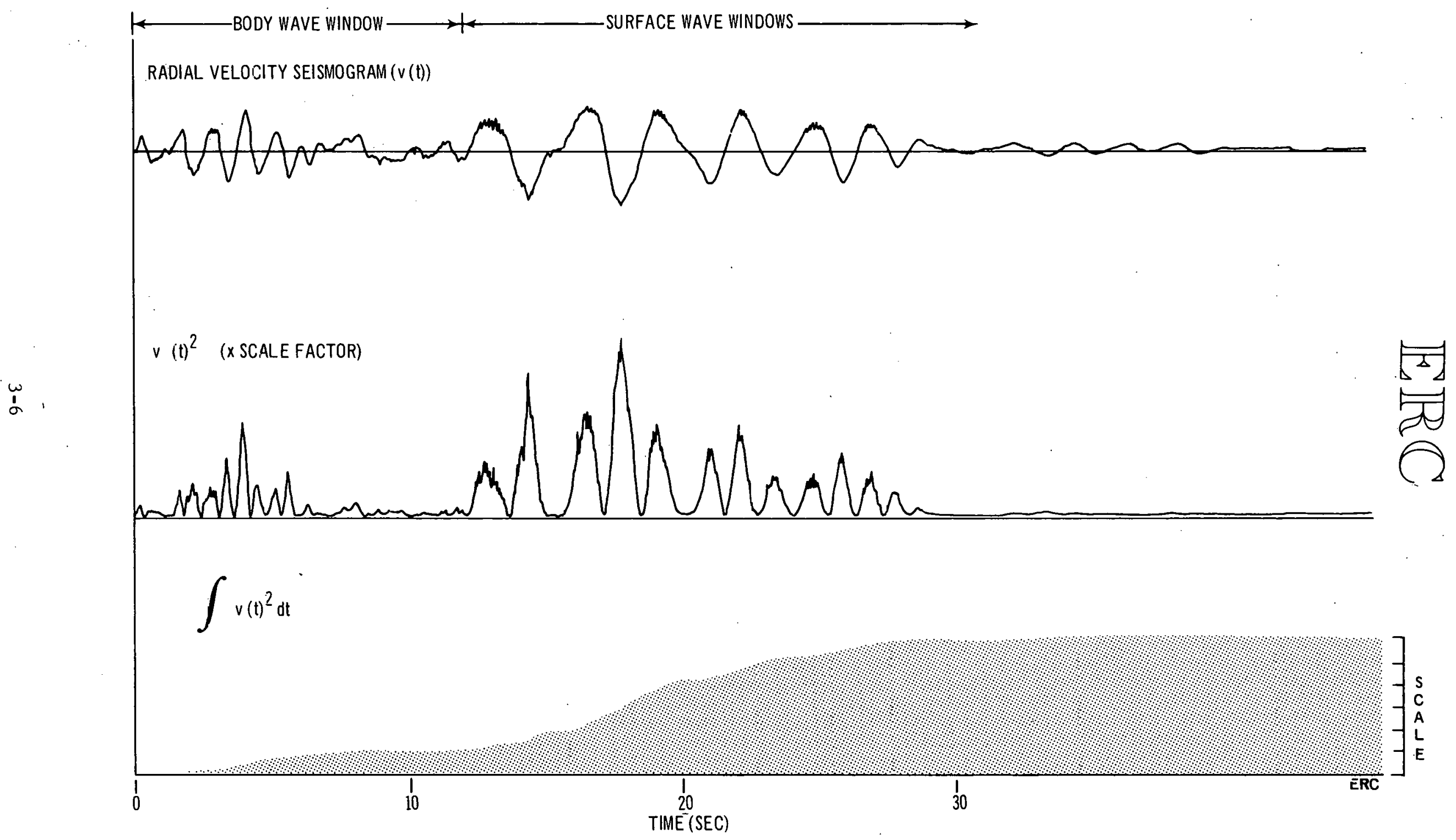

Figure 14. Approximate Energy Flux for Beatty Hardrock Radial Velocity Time History 


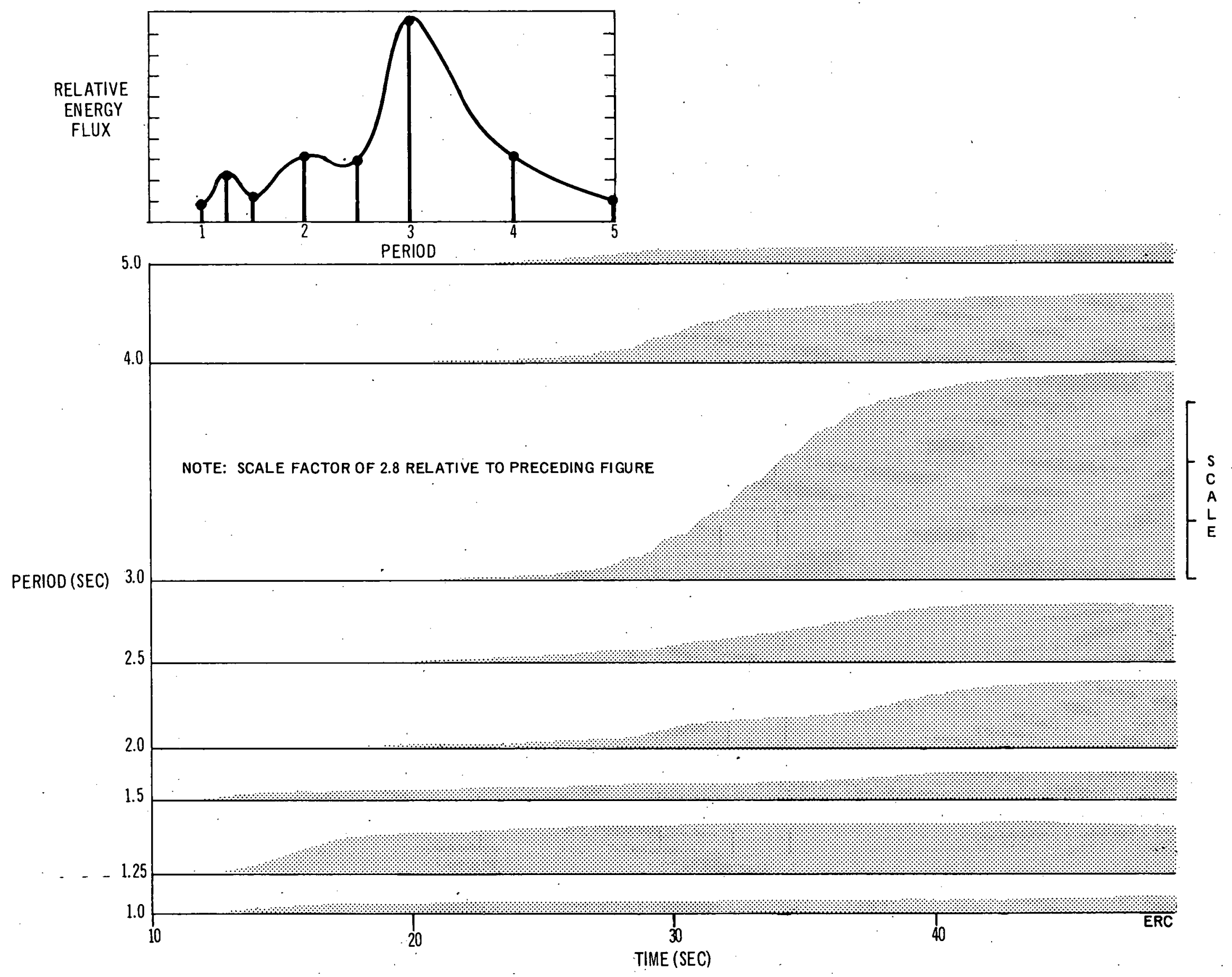

Figure 15. Approximate Energy Flux for Selected Spectral Components, Beatty Hardrock Radial Velocity Time History 


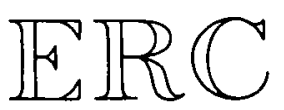

Particle motion diagrams for the surface wave window of the Handley hardrock time history are illustrated in Figure 16. The time history response of the 5\% PSRV filter having a 2.0 second center period is plotted. Motion in the vertical-radial plane is plotted on the left and in the transverse-radial plane on the right of Figure 16. The R-7. plot depicts the retrograde, elliptical motion typical of Rayleigh waves; the $\mathrm{R}-\mathrm{T}$ plane motion indicates polarization which is principally confined to a radial plane. The axis of the ellipse describing the particle motion in the $\mathrm{R}-\mathrm{Z}$ plane is strongly tilted. The reason. for this tilting is not clear, but it seems to be related to the presence of a thin, near-surface layer of low velocity materfal overlying a much higher velocity material. Observations of flattening of the particle motion ellipse have been reported for long-period Rayleigh waves from earthquakes (Dorman and Prentiss, 1960). This effect has also been noted by Boore and Toksöz (1969) in theoretical studies of propagation in layered models.

\subsection{FREQUENCY DEPENDENT SITE AMPLIFICATION}

Information about frequency dependent site amplification can be gained from analysis of response envelopes derived from the Beatty seismogram pair recorded from Handley. Figure 17 exhibits the ratio of response envelopes derived from the Beatty alluvium radial velocity seismogram to corresponding response envelopes derived from the hardrock radial velocity seismogram. The figure illustrates the time dependent response envelope ratios for the body wave window at 8 different periods ranging from $0.1-0.5$ seconds. These ratios show that the greatest amplification correlates with the shear wave arrivals and occurs at 0.33 second period. The frequency-dependent 


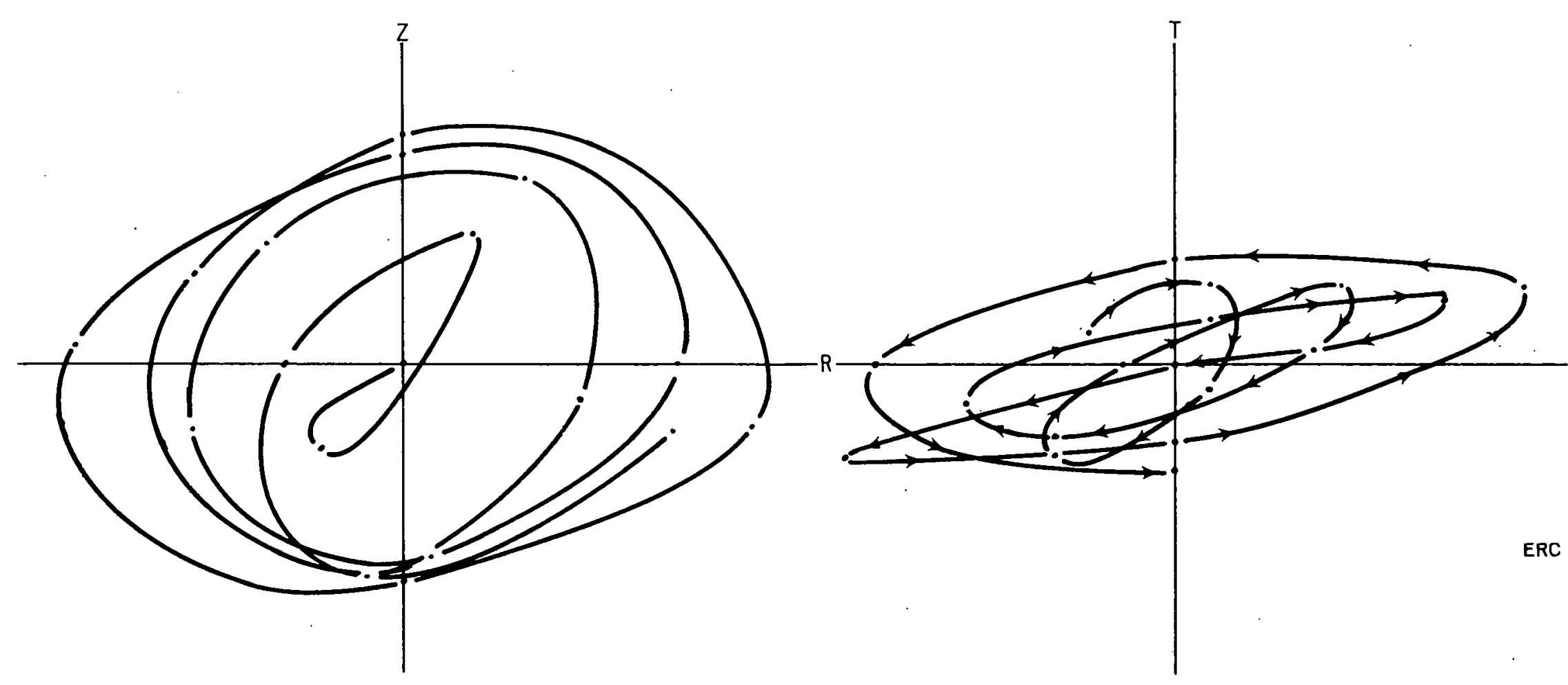

- 0.5 SECOND TIME INTERVALS

Figure 16. Particle Motion in the Rayleigh wave Time Window Obtained from 2.0 second Filtered Velocity Time History, Beatty'Hardrock 
$\mathbb{E} \mathbb{R} \mathbb{C}$

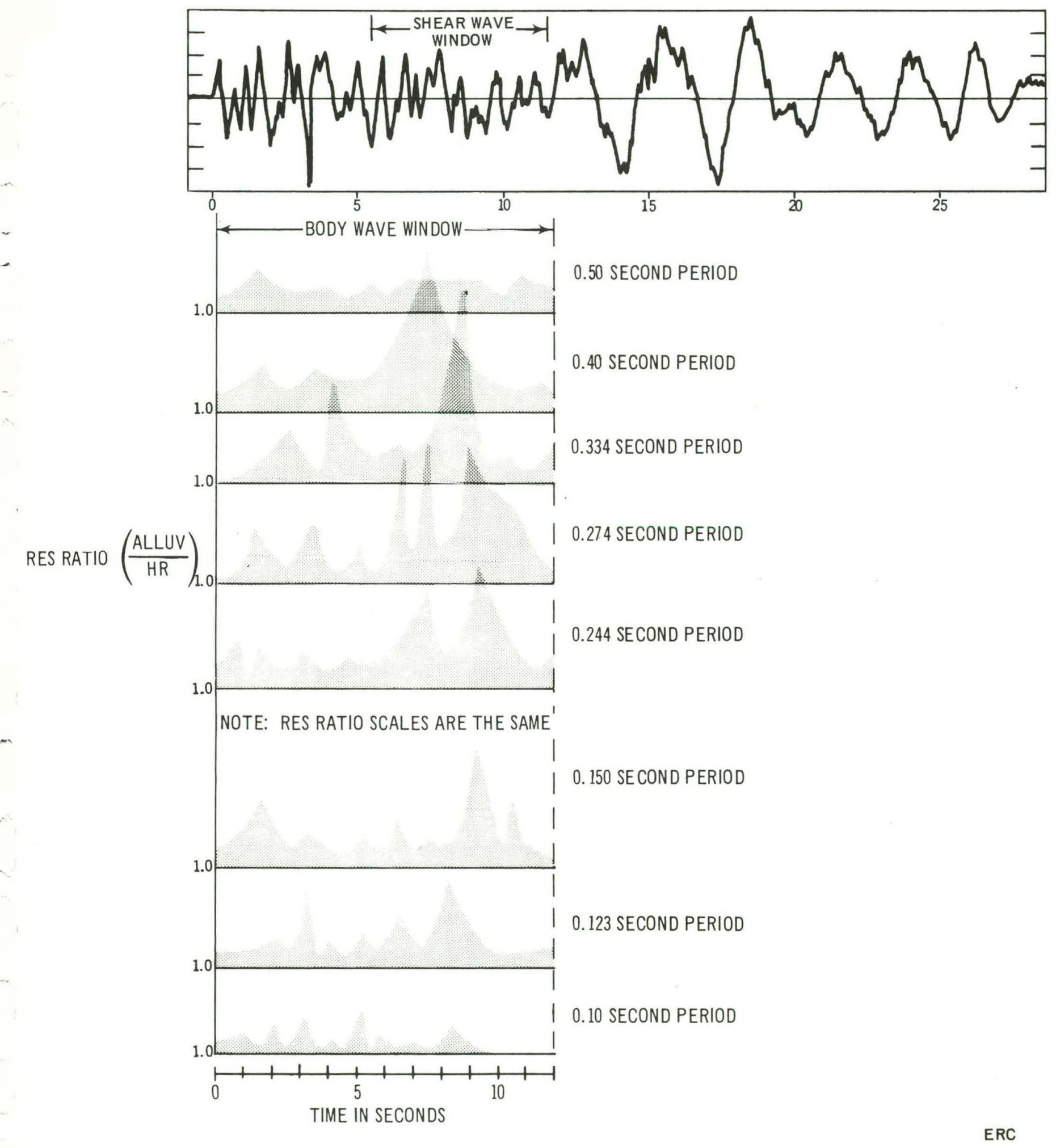

Figure 17. Radial Component Seismogram from Alluvium Station and Body Wave Amplification from Ratios of Velocity Response Envelopes, Beatty, Nevada 


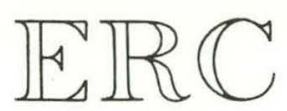

effect is manifest across a band of several periods and is quite complex.

Figure 18 illustrates the same information shown in Figure 17, but in a contour map view. The resonance effect noted earlier extends across a band of several periods, attains a maximum amplitude of about 15, and is quite complex in its time and frequency distribution. Such a display contains diagnostic information of the type needed in geotechnical analyses of soil response to ground motion loading. The information content of such a display greatly exceeds that of the amplification function shown in Figure 19. The latter figure is based on the ratio of $5 \%$ damped PSRV spectra corresponding to the alluvium and hardrock time histories.

\subsection{DURATION OF GROUND MOTION}

Figure 20 illustrates radial-component velocity time histories recorded at the Beatty hardrock station from 2 NTS nuclear detonations, Handley and Purse. The epicentral distances are approximately equal (about 29 miles). The Handley yield greatly exceeds the Purse yield, however. The respective peak amplitudes differ by a factor of 5 and are normalized for ease of comparison. Essential features of the two waves trains appear to be practically identical.

Figure 21 illustrates the comparison of corresponding velocity response envelopes, derived from the Purse and Handley seismograms, for two spectral components. This figure shows the usefulness of response envelopes for quantifying the duration of ground motion in terms of each spectral component of the seismogram. Any one of several criteria can be used to evaluate the duration of ground motion (Rogers, 1972). In this 


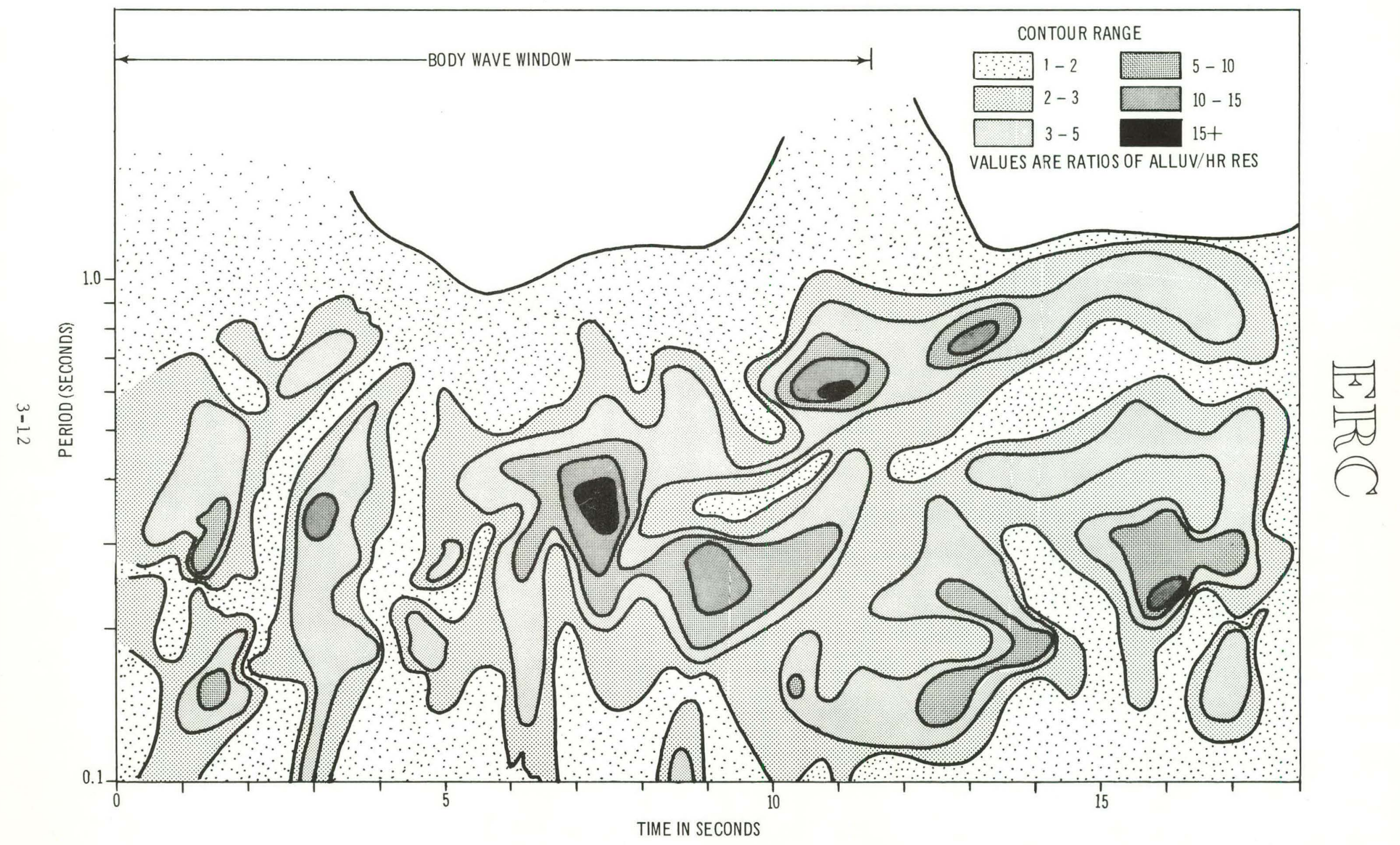

Figure 18. Contour Plot of Amplification in Body Wave Window 


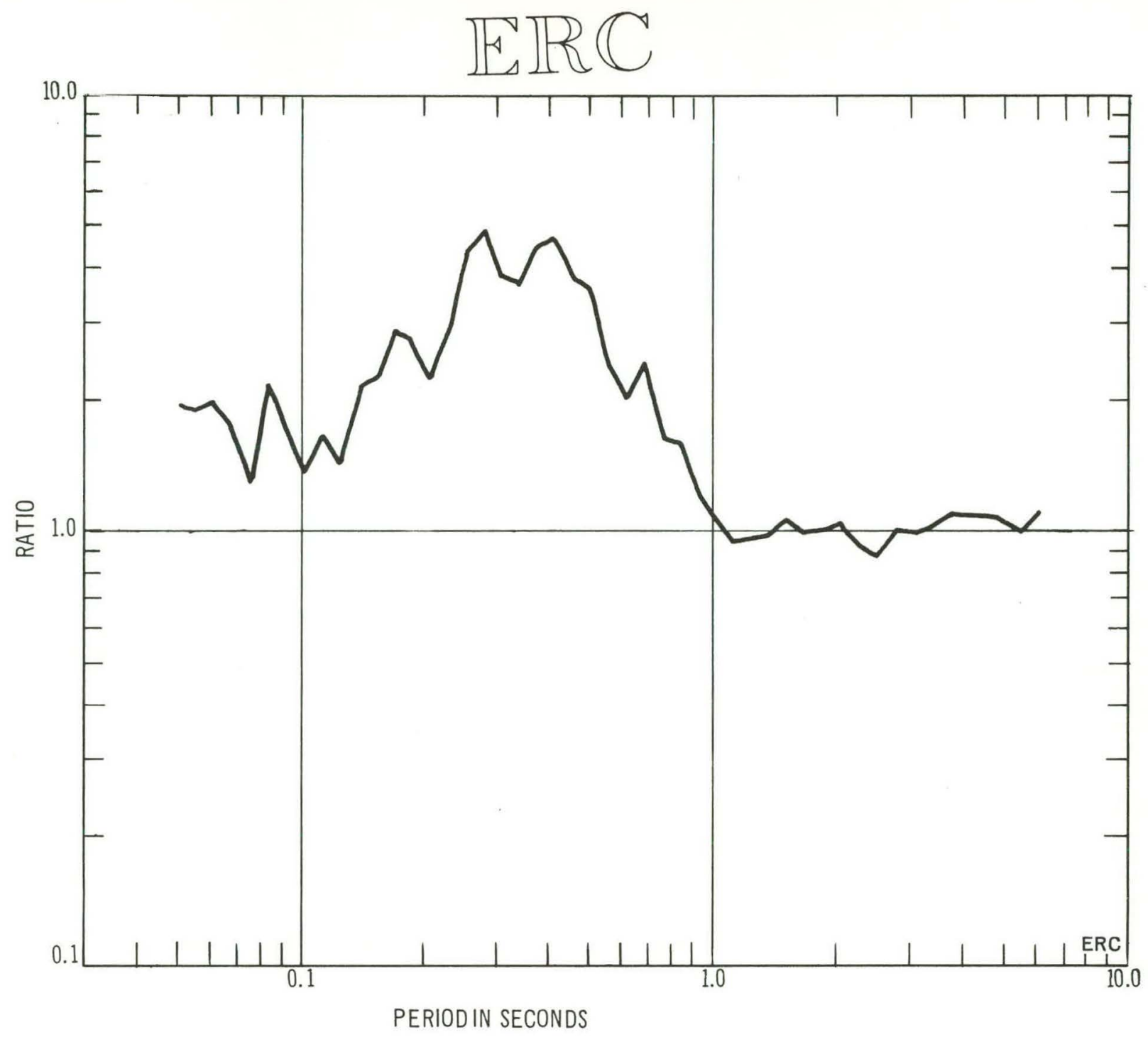

Figure 19. Ratio of Corresponding Beatty Alluvium and Hardrock Radial Component 5\% PSRV Spectra, Handley Event 


\section{HANDLEY}
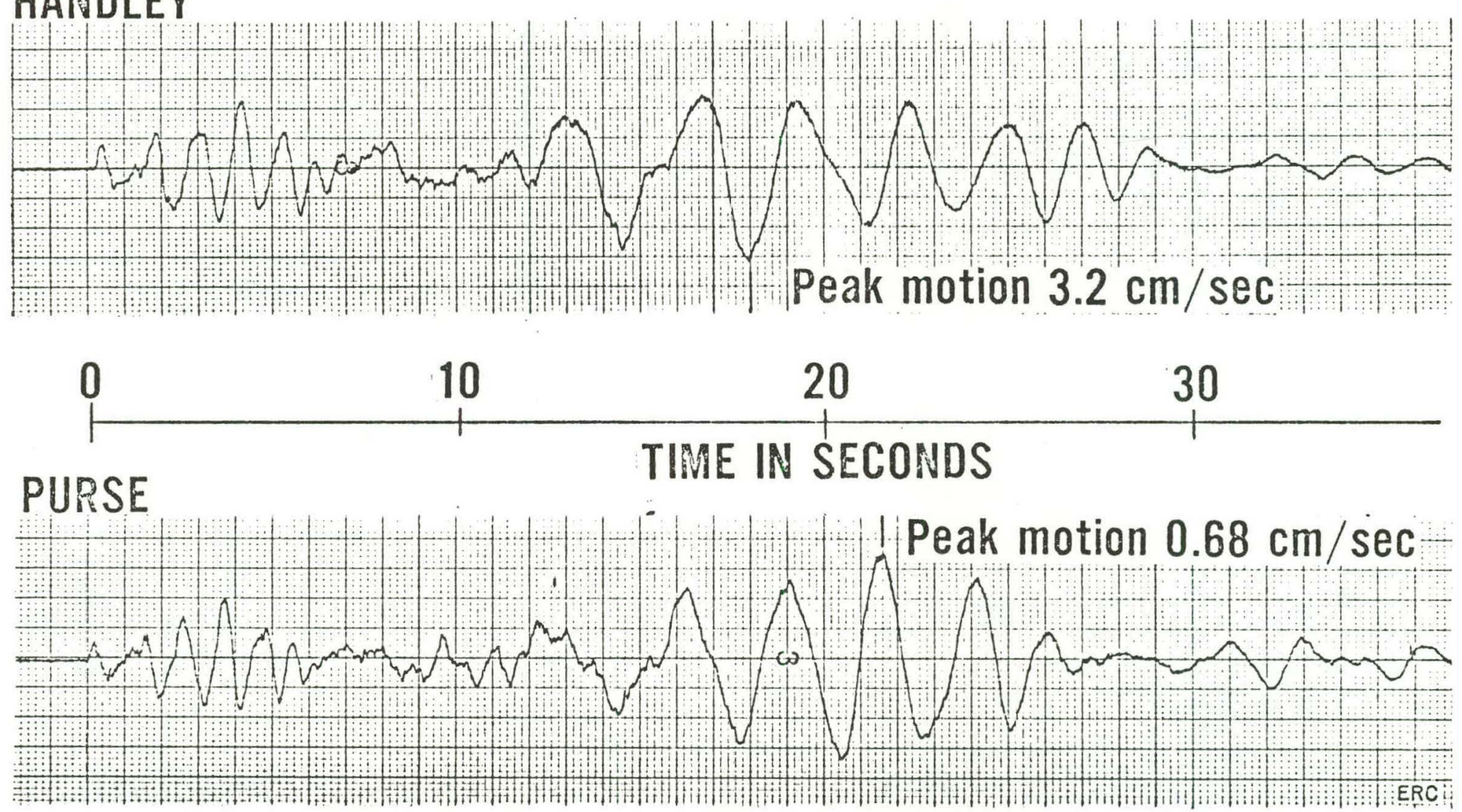

Figure 20. Time Histories of Radial Component of Ground Motion for Purse and Handley Events Recorded at Beatty, Nevada 


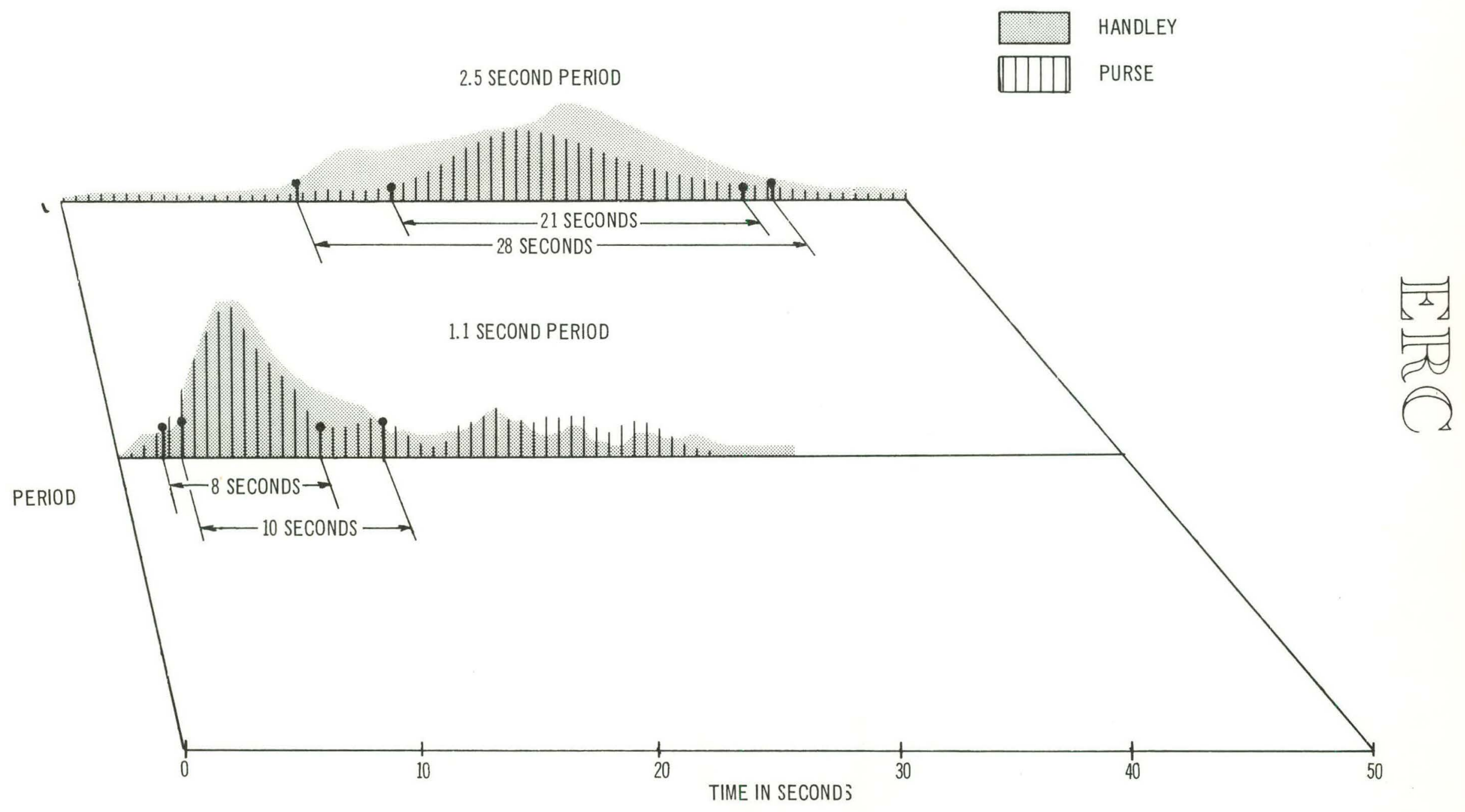

Figure 21. Example of Nuclear Explosion Duration Measurements Using Velocity Response Envelopes 


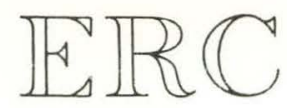

case, the criterion selected for comparison of duration is the length of time the response envelopes exceed $25 \%$ of the peak amplitude of the envelope. Using this criterion, the Handley response envelopes are seen to exhibit $25-35 \%$ greater duration than the corresponding Purse response envelopes. Handley produced longer durations than Purse over the entire spectral range.

The duration of earthquake ground motion is of considerable interest in earthquake engineering. Empirical duration relationships have been derived fror the limited earthquake data sample available prior to the 1971 San Fernando earthquake. These relationships are not very satisfactory due to their qualitative nature and the scatter in the data. These relationships suggest, however, that the duration of shaking depends strongly on the Richter magnitude; the greater the magnitude the longer the duration. Response envelopes are a useful tool for examining this relationship. Figures 22 and 23 illustrate horizontal component velocity response envelope spectra for two well known earthquakes, E1 Centro (1940) and Parkfield (1966), both recorded in the near field. Comparison of individual velocity response envelopes shows that the spectral components of the magnitude $7.0 \mathrm{E} 1$ Centro quake generally persist at greater levels for longer time intervals than corresponding spectral components of the magnitude 5.6 Parkfield quake. Figure 24 illustrates the comparison of two specific velocity response envelopes. Applying the same duration criterion used above to compare Handley and Purse ground motion durations, the E1 Centro ground motions exhibit 50-150\% 1onger durations for these two spectral components. 


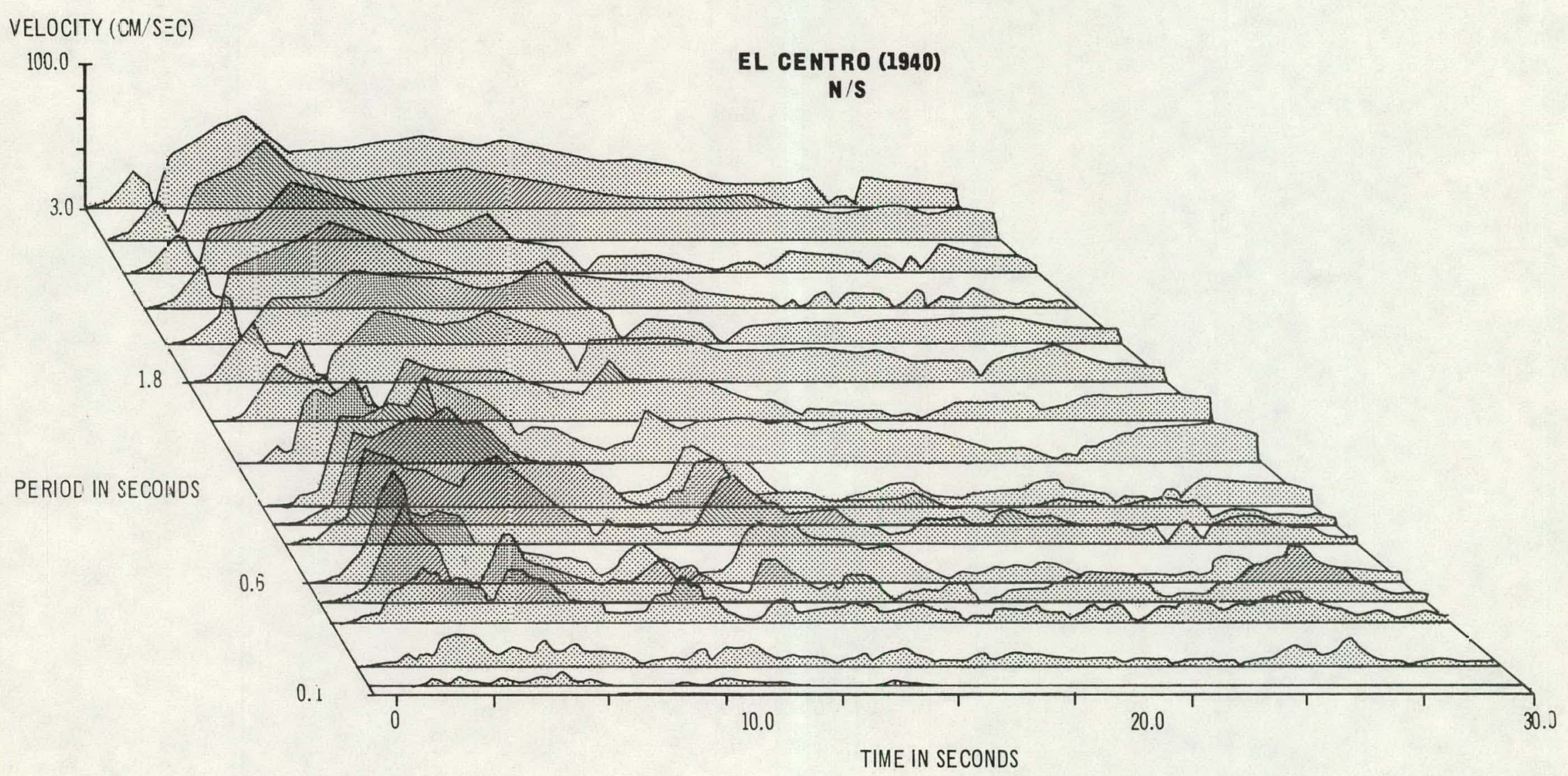

Figure 22. Response Envelope Spectrum, E1 Centro (1940) N/S Ground Motion (Adapted from United States Atomic Energy Cormission Report, NVo-118) 


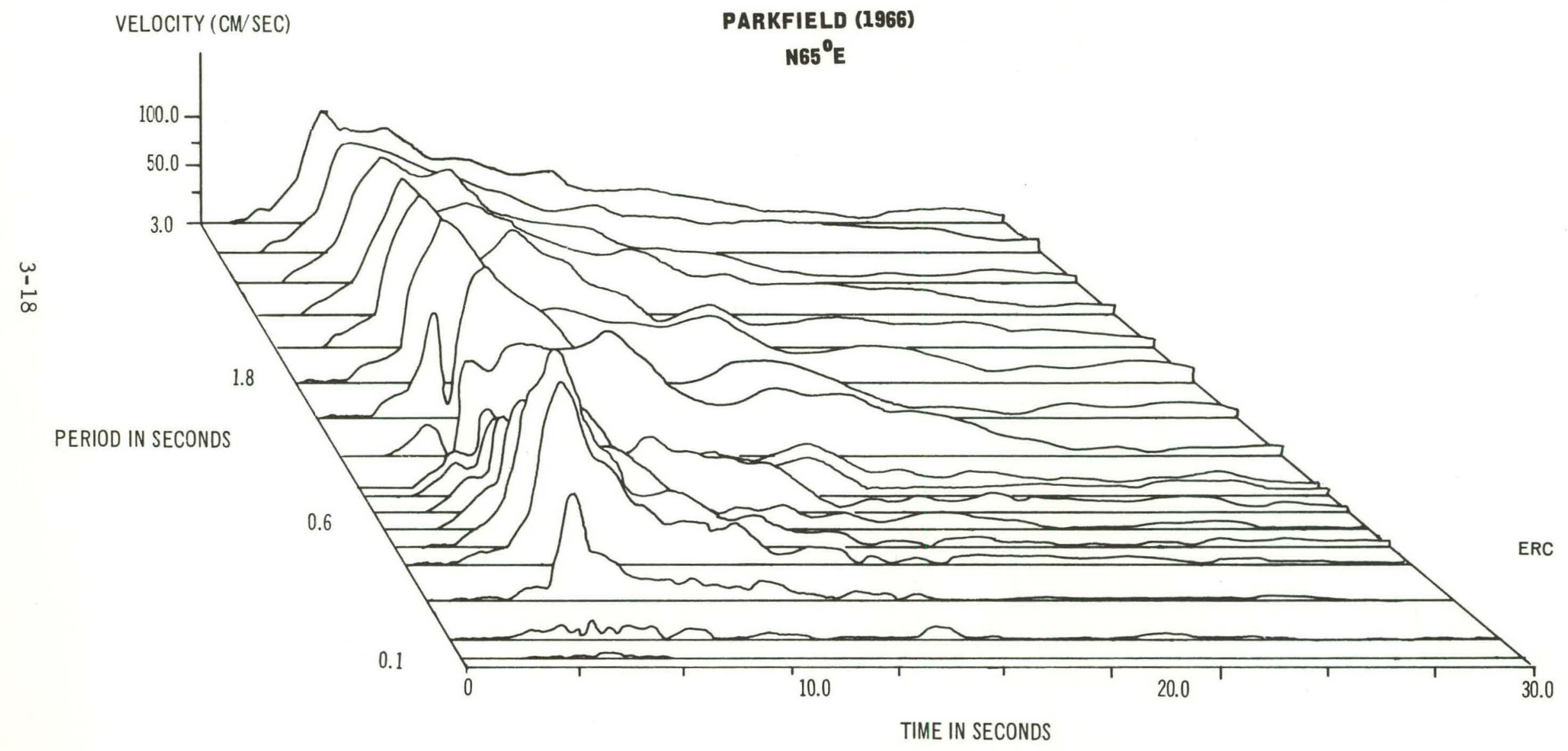

Figure 23. Response Envelope Spectrum, Parkfield (1966) N $65^{\circ}$ E Ground Motions (Adapted from United States Atomic Energy Commission Report, NVO-118) 


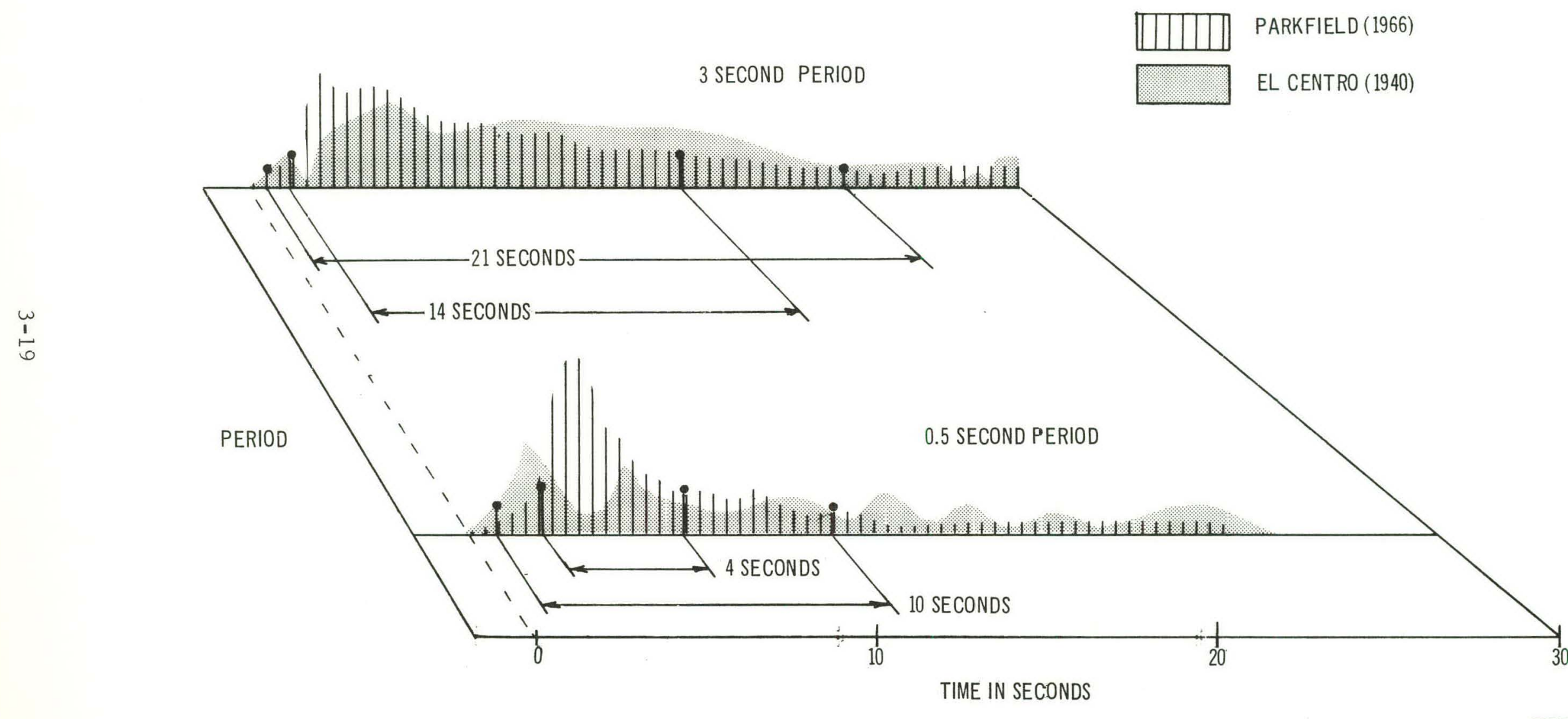

ERC

Figure 24. Example of Earthquake Duration Measurements Using Velocity Response Envelopes 


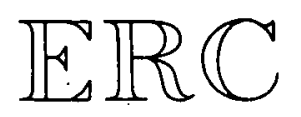

These results about ground motion duration are preliminary. More research is needed to validate these trends for nuclear explosion and earthquake ground motion duration. In particular, the effects on ground motion duration of discrete parameters of the seismic wave propagation system need to be isolated. 


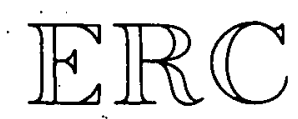

\section{SECTION 4}

DISCUSSION

\subsection{SUMMARY}

The seismogram pair recorded at Beatty, Nevada, represents a useful data base for evaluating the utility of time dependent spectral analysis techniques in ground motion studies. The two Beatty stations have recorded ground motion from a large number of nuclear events, thus the seismic response characteristics are well known.

The Beatty ground motion time histories are characterized by a prominent dispersive Rayleigh wave train. Response time histories and time dependent response envelopes can be used efficiently to extract information from the seismogram about group velocity, relative energy flux, and particle motion of the surface wave train. This information provides improved insight into complex surface wave propagation phenomena.

The frequency dependent amplification effect exhibited at the Beatty alluvium station has been recognized for several years. Response envelopes provide clearer resolution of this complex effect in terms of its time and frequency distribution and hold promise for analysis of non-linear soil effects.

Response envelopes appear to be useful analysis tools for quantifying the duration of ground motion in terms of individual spectral components. Preliminary evaluation of Handley and Purse ground motions recorded at Beatty suggests that the duration of nuclear detonation generated ground motion increases slightly with increase in energy release. Corresponding 


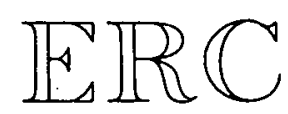

evaluation of the El Centro and Parkfield earthquake ground motions suggests a stronger dependence of duration on energy release.

Response time histories, time dependent response envelopes, and response envelope spectra are useful signal analysis tools. They significantly improve the engineering seismologist's capability to study ground motion phenomena. 


\section{REFERENCES}

Alexander, S., 1963, Surface Wave Propagation in the Western US, Ph.D Thesis, California Institute of Technology.

Archambeau, C. B., E. A. Flinn, and D. G. Lambert, 1966, Detection, Analysis, and Interpretation of Teleseismic Signals, I., Compressional Phases From the Salmon Event, J. Geophysical Research, V. 71, p. 34833.501.

Benioff, H., 1934, The Physical Evaluation of Seismic Destructiveness, Bull. Seism. Soc. Am. 24, 398.

Biot, M. A., 1943, Analytical and Experimental Methods in Engineering Seismology, Transactions, Am. Society of Civil Engineers, V. 108, p. 365 .

Blume, J. A., N. M. Newmark, and L. K. Corning, 1961, Design of Multistory Reinforced Concrete Buildings for Earthquake Motions, Portland Cement Association, Chicago, Illinois.

Boore, D. M. and M. N. Toksöz, 1969, Rayleigh Wave Particle Motion and Crustal Structure, Bull. Seism. Soc. Am. 59, p. 331-346.

Dorman, J. and D. Prentiss, 1960, Particle Amplitude Profiles for Rayleigh Waves on a Heterogeneous Earth, J. Geophys. Res. 65, p. 3805-3816.

Dunkin, J. W., 1965, Computation of Model Solutions in Layered, Elastic Media at High Frequencies, Bull. Seism. Soc. Am. 55, p. 335-358.

Dziewonski, A., S. Bloch, and M. Landisman, 1969, A Technique for the Analysis of Transient Seismic Signals, Bull. Seism. Soc. Am. 59, p. 427-444.

Dziewonski, A., J. Mills, and S. Bloch, 1972, Residual Dispersion Measurement-A New Method of Surface Wave Analysis, Bull. Seism. Soc. Am. 62, p. 129-140.

Haske11, N. A., 1953, The Dispersion of Surface Waves in Multilayered Media, Bull. Seism. Soc. Am. 43, p. 17-34.

Hudson, D. E., 1956, Response Spectrum Techniques in Engineering Seismology, Proceedings, World Conference on Earthquake Engineering, Earthquake Engineering Research Institute, . Berkeley, California, p. 4.1.

Jenschke, V. A., R. W. Clough, and J. Penzien, 1969, Characteristics of Strong Ground Motions, Proceedings, Third World Conference on Earthquake Engineering, New Zealand, VI, p. III-125-142. 


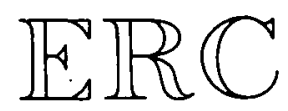

REFERENCES

(Continued)

Johnson, L. R., 1965, Crustal Structure Between Lake Mead, Nevada, and Mono Lake, California, J. Geophys. Res. 70, p. 2863-2872.

Landisman, M., A. Dziewonski, and Y. Sato, 1969, Recent Improvements in the Analysis of Surface Wave Observations, Geophys. J. 17, p. 369403 .

Lynch, R. D., 1965, Analog Computer Analysis of Magnetic Tape Seismograms, Environmental Research Corporation Report NV0-1163-4l, AEC, (Available from NTIS).

Ohsaki, Y., 1969, The Effects of Local Soil Conditions Upon Earthquake Damage, Proceedings, Soil Dynamics Specialty Session 2, Seventh International Conference of Soil Mechanics and Foundation Engineering, Mexico City, p. 3.

Perez, V., 1973, Velocity Response Envelope Spectrum as a Function of Time, Pacoima Dam, San Fernando Earthquake, February 9, 1971, Bull. Seism. Soc. Am. 63, February, (in press).

Pilant, W. L. and L. Nopoff, 1964, Observations of Multiple Seismic Events, Bull. Seism. Soc. Am. 54, p. 19-39.

Rogers, A. M., 1972, The Question of Ground Motion Duration for Nuclear Detonations and Earthquakes, Environmental Research Corporation Report, NVO-1163-TM-34, AEC, (Available from NTIS).

Sutton, G. and P. Pomeroy 1953, Analog Analyses of Seismograms Recorded on Magnetic Tape, J. Geophys. Res. 68, p. 2791-2815.

Trifunac, M. D., 1971, Response Envelope Spectrum and Interpretation of Strong Earthquake Ground Motion, Bull. Seism. Soc. Am. 61, p. 343356.

United States Atomic Energy Commission, Nevada Operations Office, Proceedings of the Structural Response Seminar, August 25, 1971, NVO-118, p. 22, 63 . 
Distribution for NVO-1163-TM-37

Mr. R. H. Thalgott, AEC/NV, Las Vegas, Nevada

Dr. E. M. Douthett, AEC/NV, Las Vegas, Nevada

Mr. P. N. Halstead, AEC/NV, Las Vegas, Nevada

$\mathrm{Mr}$. B. G. DiBona, AEC/NV, Las Vegas, Nevada

$\mathrm{Mr}$. R. M. Pastore, AEC/NV, Las Vegas, Nevada

Technical Library, AEC/NV, Las Vegas, Nevada (3 copies)

$\mathrm{Mr}$. R. R. Loux, AEC/NV, Las Vegas, Nevada

$\mathrm{Mr}$. R. Ray, AEC/NV, Las Vegas, Nevada

Mr. R. Hamburger, AEC/DAT, Washington, D. C.

AEC/DMA, Hq., Washington, D. C.

AEC/DAT, Hq., Washington, D. C.

TIC, Oak Ridge, Tennessee (2 copies)

Dr. J. R. Banister, Sandia Labs., Albuquerque, New Mexico

Dr. M. L. Merritt, Sandia Labs., Albuquerque, New Mexico

Dr. D. Ellett, Sandia Labs., Albuquerque, New Mexico

Technical Library, Sandia Labs., Albuquerque, New Mexico

Dr. W. D. Weart, Sandia Labs., Albuquerque, New Mexico

Dr. J. E. Carothers, LLL, Livermore, California

Dr. J. W. Hadley, LLL, Livermore, California

Dr. Fred Holzer, LLL, Livermore, California

Dr. L. S. Germain, LLL, Livermore, California

Dr. Norman Pruvost, LLL, Livermore, California

Mr. Howard Rodean, LLL, Livermore, California

Dr. C. I. Browne, LASL, Los Alamos, New Mexico

Dr. Ken 01sen, LASL, Los Alamos, New Mexico

Dr. A. H. Davis, LASL, Los Alamos, New Mexico

Mr. R. W. Newman, LASL, Los Alamos, New Mexico

Dr. John A. Blume, John A. Blume \& Associates, San Francisco, California

Mr. R. E. Skjei, John A. Blume \& Associates, Las Vegas, Nevada

Dr. W. S. Twenhofel, USGS, Denver, Colorado

Mr. P. L. Russe11, USBM, Denver, Colorado

Mr. Paul Fillo, USBM, Carson City, Nevada

Mr. K. W. King, ESL, Las Vegas, Nevada ( 2 copies)

Dr. Benjamin Grote, TCDT-E, TC/DNA, Sandia Base, Albuquerque, New Mexico

Environmental Research Corporation, Las Vegas, Nevada (3 copies) 